\title{
Plasmalemmal Undercoat: The Cytoskeleton Supporting the Plasmalemma
}

\author{
Harunori ISHIKAW A \\ Department of Anatomy, Gunma University School of Medicine, Maebashi, Japan
}

Received March 30, 1988

\begin{abstract}
Summary. The plasmalemmal undercoat can be defined as the electron-dense material of layered organization closely applied to the cytoplasmic surface of the plasma membrane (plasmalemma) as revealed by thin-section electron microscopy. Though the structures which fulfill this criterion occur widely, most of them have not received the attention they may deserve. The undercoat is a special form of the cytoskeletonmembrane interaction, though it constitutes a part of the cytoskeleton. The significance of the plasmalemmal undercoat may be primarily to provide a structural support for the membrane. With this support, cells can perform many important functions on their limited or whole surfaces. The undercoat may provide a mechanical support to the plasmalemma so that the membrane may acquire rigidity, strength and elasticity. Through association with the membrane, the undercoat may regulate the distribution of integral membrane proteins to form and maintain various functional domains on the plasmalemma. The undercoat may further provide attachment sites for cytoskeletal fibrous components such as actin filaments, intermediate filaments and microtubules.
\end{abstract}

For the molecular architecture of cellular membranes, the fluid mosaic model is now widely accepted. In this model, lipids are arranged in a fluid bilayer within which integral membrane proteins are embedded in a mosaic manner, whereas peripheral membrane proteins are closely associated with the cytoplasmic surface of the membrane proper (SINGER and NiCOL. SON, 1972). The integral proteins can move laterally within the plane of the membrane (NICOLSON, 1976). Various membrane phenomena such as membrane fusion, fluidity and deformability are better explained by this model. Similarly, the ultrastructure of cellular membranes as revealed by electron microscopy can be well interpreted on the basis of this model. However, the membrane properties to be expected from the flluid mosaic model may not always be advantageous for every cell. Indeed, such properties do not appear to be unlimitedly expressed in cellular membranes, especially in the plasmalemma.

Many types of cells develop functional specializations or domains on their cell surfaces. Such domains may be identified as sites of ion transport, cell adhesion, the attachment of cytoplasmic fibrous structures, and so on. Evidence has been accumulated showing that functional and/or structural membrane proteins are specifically localized in such domains. It is of great interest to elucidate the mechanisms by which such functional domains are maintained in the fluid and continuous plasmalemma.

The localization of specific functions to the plasmalemma may partly be attributed to the molecular interaction of lipids and proteins within the membrane. The structural support for the functional localization may be provided from the outside of the membrane itself. The surface coat or glycocalyx may possibly be involved cooperated with the extracellular matrix composed of collagen, laminin, fibronectin, etc. However, it should be emphasized that the major structural support for the membrane is given by cytoplasmic components. Thin-section electron microscopy has revealed electron-dense structures applied to the cytoplasmic surface of the plasmalemma in areas where certain specific functions are expected to be localized. Such underlying structures occur widely in various cell types. These observations have led us to propose a concept of the plasmalemmal undercoat as the cytoskeleton that structurally supports the plasmalemma (IsHIKAWA et al., 1981, 1982). In this article, the morphological aspects of the plasmalemmal undercoat are presented and discussed with special reference to its functional significance. 


\section{OCCURRENCE AND ULTRASTRUCTURE OF PLASMALEMMAL UNDERCOAT}

The interaction between the plasmalemma and the cytoplasmic matrix has drawn much attention from cell biologists. The major structural components of the cytoplasmic matrix are fibrous structures, such as microtubules, actin-containing microfilaments, and intermediate filaments, which constitute the cytoskeleton. These fibrous structures are closely associated with the plasmalemma in various manners. The most common form of association seems to be the indirect binding of these fibrous components to the membrane via peripheral membrane proteins that bind integral membrane proteins. Such binding often involves specialized devices, which represent the plasmalemmal undercoats.

\section{Plasmalemmal undercoats in nerve fibers}

The plasmalemmal undercoat is morphologically defined as the specialized structure of a layered organization closely applied to the cytoplasmic surface of the plasmalemma. Typical examples are found at the initial segments and the nodes of Ranvier of myelinated axons (PALAY, 1964; PETERS, 1968). In these regions the generation and saltatory conduction of action potentials are believed to occur. The plasmalemma (or axolemma) of these regions appears thickened in low-power electron micrographs (Fig. 1). At higher magnification the membrane proper is never seen to thicken, showing the characteristic trilamellar structure. Instead, an electron-dense layer is closely applied to the inner aspect of the axolemma (ISHIKAWA et al., 1981). Such a specific layer is not found in any other region of the axon, though some thin, fuzzy layers may be seen along the axolemma of the internodes (TsukITA and ISHIKAWA, 1980). The ultrastructural details of the undercoat were first described by CHAN-PALAY (1972) for the initial segments of myelinated axons in the central nervous system. The undercoats at both the initial segments and nodes of Ranvier can be resolved to comprise perpendicular and parallel components. Perpendicular components of granular or rod-like configurations appear to bridge the plasmalemma proper with a $20 \mathrm{~nm}$ thick layer of parallel components, with which underlying microtubules and neurofilaments are associated (Fig. 1). Freeze-fracture replica studies have demonstrated that the axolemma at the node of Ranvier is characterized by the occurrence of large intramembranous particles approxi- mately $20 \mathrm{~nm}$ in diameter, which are considered to represent sodium channels (RosEnBLUTH, 1976).

Recently, KoHNo et al. (1986) have examined in detail the undercoat at the initial segments of Mauthner cells in the medulla oblongata of the goldfish. Beneath the axolemma is seen a dense plate composed of 7.5 $\mathrm{nm}$ particles $10 \mathrm{~nm}$ apart from the membrane. The dense plate is further underlaid with parallel bundles of $5 \mathrm{~nm}$ filaments which are arranged longitudinally at distances of $130 \mathrm{~nm}$ and $90 \mathrm{~nm}$ alternately. Larger filaments about $10 \mathrm{~nm}$ thick are also closely associated with the dense plate and run longitudinally between the bundles. In freeze-fracture replicas, large intramembranous particles are aligned in parallel rows spaced $200 \mathrm{~nm}$ apart, which corresponds to the course of these $10 \mathrm{~nm}$ filaments.

\section{Erythrocyte membrane cytoskeleton}

The molecular organization of the human erythrocyte membrane has been extensively studied, for which the existence of a two-dimensional network of the cytoplasmic surface of the membrane has been emphasized (for reviews see STECK, 1974; MARCHESI et al., 1976; BRANTON et al., 1981; BENNETT, 1982; MARCHESI, 1983; COHEN, 1983). Various electron microscopic approaches have been taken to visualize the network. The scanning electron microscope was first used to successfully demonstrate the submembranous reticula of human erythrocytes after detergent treatment (HAINFELD and STECK, 1977). Other methods serving to show the network have been negative staining (SHEETZ and SAWYER, 1978) and freeze-ecthing (NERMUT, 1981). Fixation with a glutaraldehyde solution containing tannic acid has enabled a clear visualization of the continuous network underlying the membrane in thin sections (Tsu KITA et al., 1980) (Fig. 2).

The networks in isolated membrane preparations are composed of two layers: an anastomosing network of filamentous components approximately $9 \mathrm{~nm}$ thick and a layer of perpendicular components of granular appearance. The latter layer appears to connect the filamentous network to the membrane proper. The network corresponds to the insoluble residues which remain after detergent extraction of the erythrocyte ghosts. These observations, together with extensive biochemical analyses, have shown that spectrin and actin are the major constituents of the filamentous network, in which actin exists as short filaments and spectrin tetramers form flexible rods $200 \mathrm{~nm}$ long. Four to six spectrin rods attach to an actin filament to form a structural unit of 

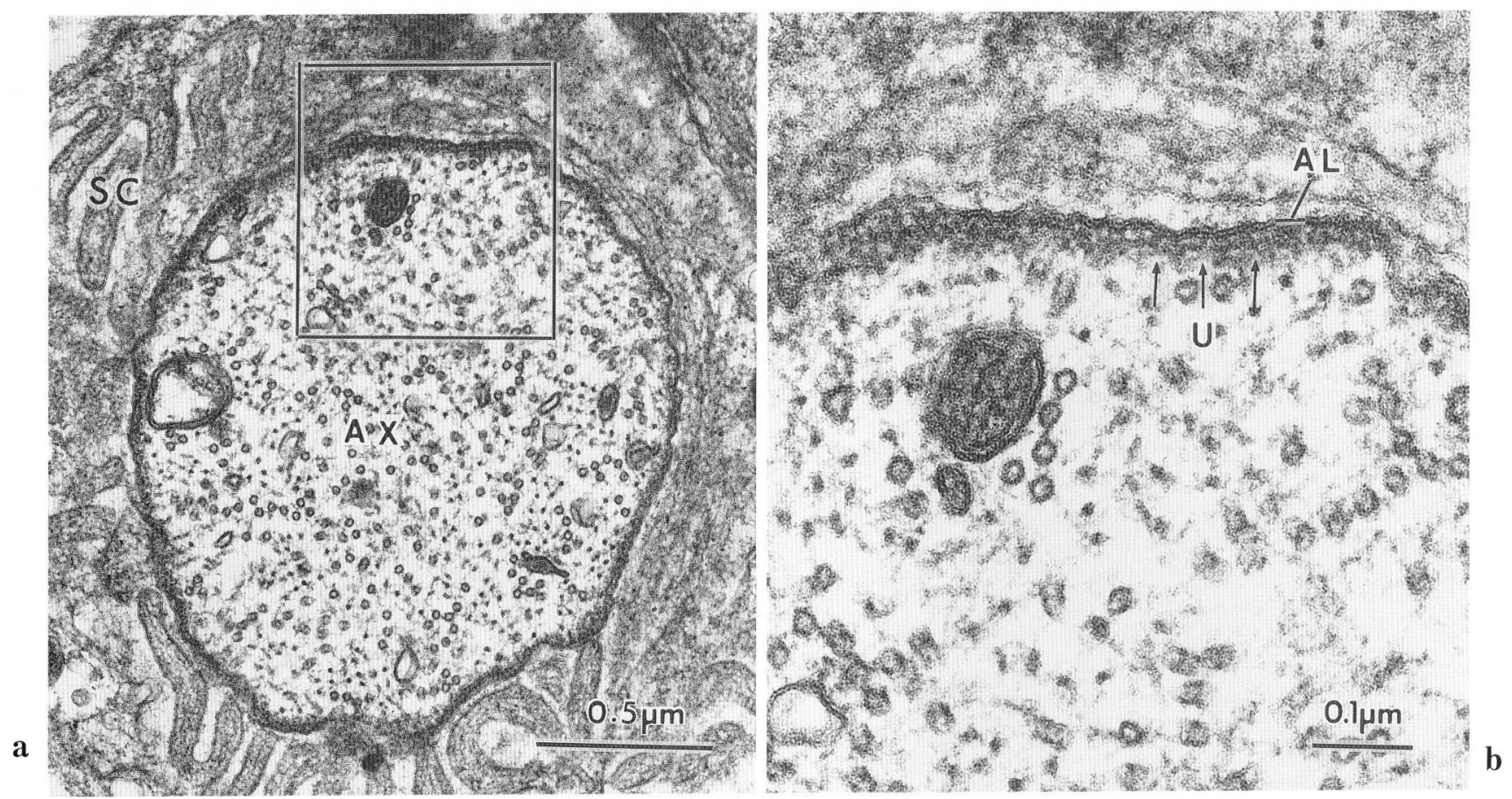

Fig. 1. Transverse section of a myelinated axon at the node of Ranvier. Rat spinal nerve. a. At the node, the axon $(A X)$, which is surrounded by many finger-like processes of the Schwann cell (SC), is characterized by an apparent thickening of the axolemma. Note comparison with the Schwann cell plasmalemma. b. Higher magnification of the area marked with the square on Figure a. The axolemma $(A L)$ is not thickened but electron-dense materials are closely applied to the cytoplasmic surface of the axolemma, showing a layered organization (arrows $U$ ).

spider-like configuration. In a sense, spectrin molecules serve as spacing factors for actin filaments. The network is believed to be connected with the plasmalemma through ankyrin and band 4.1 protein. When the human erythrocyte membrane is treated with a low ionic strength solution (0.1 mM EDTA), spectrin-actin networks are extracted, resulting in the fragmentation of the membrane into inverted vesicles and in the disappearance of the filamentous networks, leaving only granular components on the membrane surface (see Tsukita et al., 1980). The network can be reconstituted through the reassociation of spectrin and actin to such inverted vesicles (Tsukita et al., 1981). More recently, Triton-extracted erythrocyte membranes have been negatively stained to clearly visualize the filamentous network in terms of spectrin and actin in situ (SHEN et al., 1984; ByERS and BRAnTON, 1985). The network evidently constitutes the plasmalemmal undercoat or "membrane skeleton" (Lux, 1979). However, the characteristic biconcave shape of mammalian erythrocytes cannot be explaind solely by the existence of such a submembranous network. Recently, an authentic myosin has been indentified and purified from erythrocytes (FowLer et al., 1985; WONG et al., 1985). A mechanism by which myosin could interact with actin filaments of the membrane skeleton to influence the erythrocyte shape and membrane properties has been proposed (FOWLER, 1986).

There have been numerous reports on the occurrence of spectrin-like proteins (spectrin family) in a variety of non-erythroid cells including nerve cells, intestinal cells and muscle cells (LAZARIDEs and NELSON, 1982; BURRIDGE et al., 1982; GLENNEY and GLENNEY, 1983). Spectrins have been demonstrated to be situated predominantly but not exclusively in the cell cortex, especially just beneath the plasmalemma. Erythrocyte and non-erythroid spectrins share biochemical and structural characteristics, including the capability of binding to actin filaments and intermediate filaments (LANGLEY and COHEN, 1987). Likewise, ankyrin- and band 4.1-like proteins are also widely distributed in non-erythroid cells (DAVIS and BenNett, 1984; Nelson and LazARIDEs, 1984). 


\section{Plasmalemmal undercoats in synapses}

A special form of the plasmalemmal undercoat has been seen as a synaptic density in the chemical syna- pse (PETERs et al., 1976). The undercoats occur on both pre- and post-synaptic membranes. The form and degree of development of the undercoats vary among different kinds of synapses. The undercoats
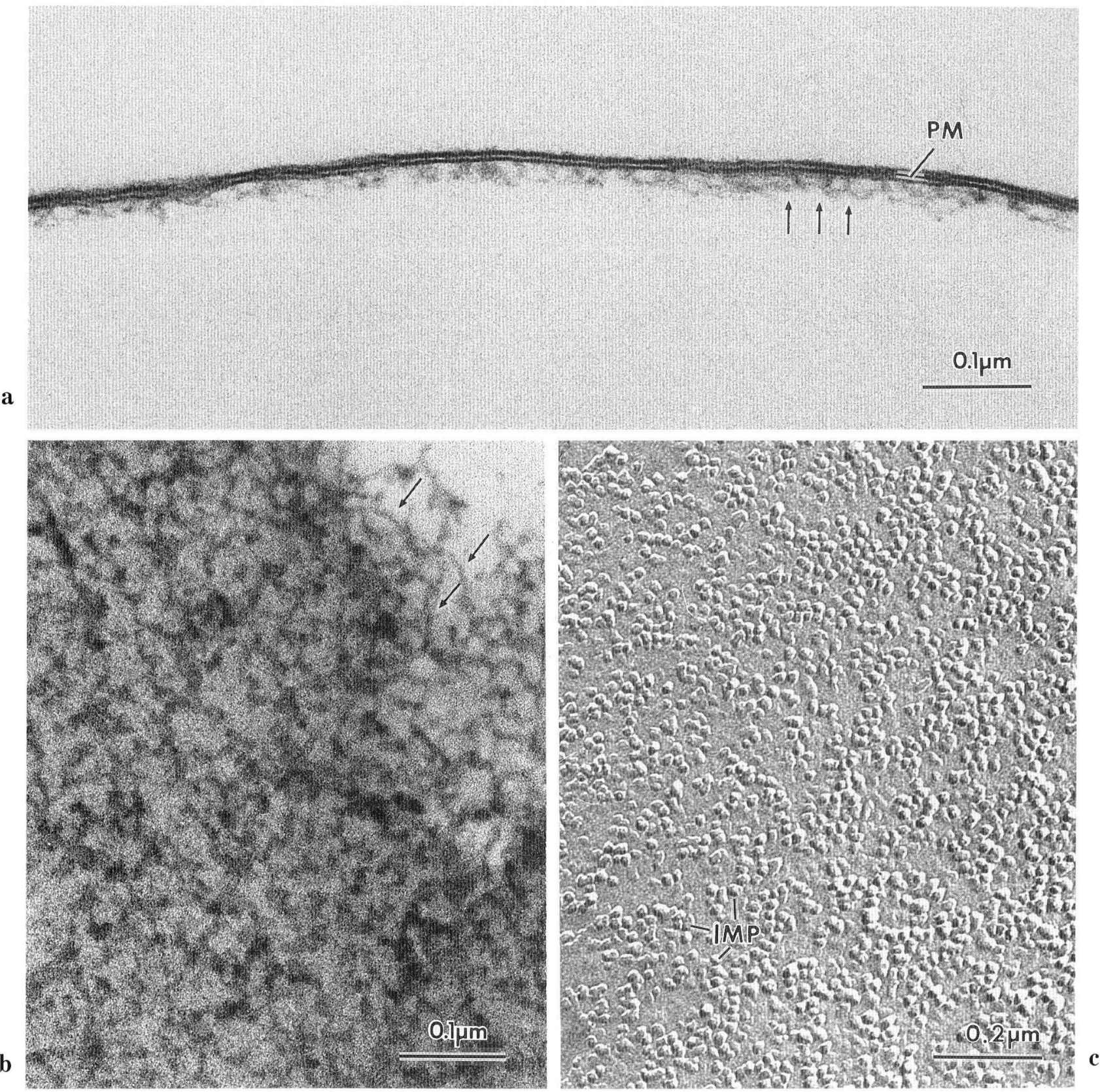

Fig. 2. Human erythrocyte membrane. a. Transverse section of the isolated erythrocyte membrane. With tannic acid-glutaraldehyde fixation, the cytoskeletal network underlying the membrane $(P M)$ is clearly visualized. The network is resolved into two layers; a layer of parallel components is linked to the membrane by a layer of perpendicular components (arrows). b. Frontal view of the cytoskeletal network. This section is cut tangentially to the membrane. The parallel components are seen to form an anastomosing meshwork of filamentous structures (arrows). c. Freeze-fracture replica image of the human erythrocyte membrane. Numerous intramembranous particles (IMP) are rather evenly distributed all over the membrane. 
are well developed on post-synaptic membranes, showing electron-dense plates or disks in the brain (PAPPAS and WAXMAn, 1975; see also COHEN and SiekEvitz, 1978). Studies with isolated synapses indicate that the density is a somewhat disk-like structure of filamentous nature, to which a network of subsynaptic web-materials is connected (MATUS and WALTERS., 1975; COHEN et al., 1977). Similar postsynaptic densities can be seen at the neuromuscular junctions (Fig. 3). To the densities are attached the cytoplasmic fine filaments, which are considered to be actin filaments (LEBEUX and WILLEMOT, 1975; GULLY and REESE, 1981) (Fig. 4a). The post-synaptic membrane of the neuromuscular junction is characterized by clusters of acetylcholine receptors (HIROKAWA and Heuser, 1982). The undercoat spatially coincides with a cluster of these receptor proteins (FERTUCK and Salpeter, 1976; Hirokawa and Heuser, 1982).

Fig. 3. Neuromuscular junction of the mouse diaphragm. The sarcolemma facing the nerve terminal $(N T)$ is seen to be underlaid with dense material (arrows $U$ ), which corresponds to the postsynaptic density of the synapse in general. $M C$ skeletal muscle cell.
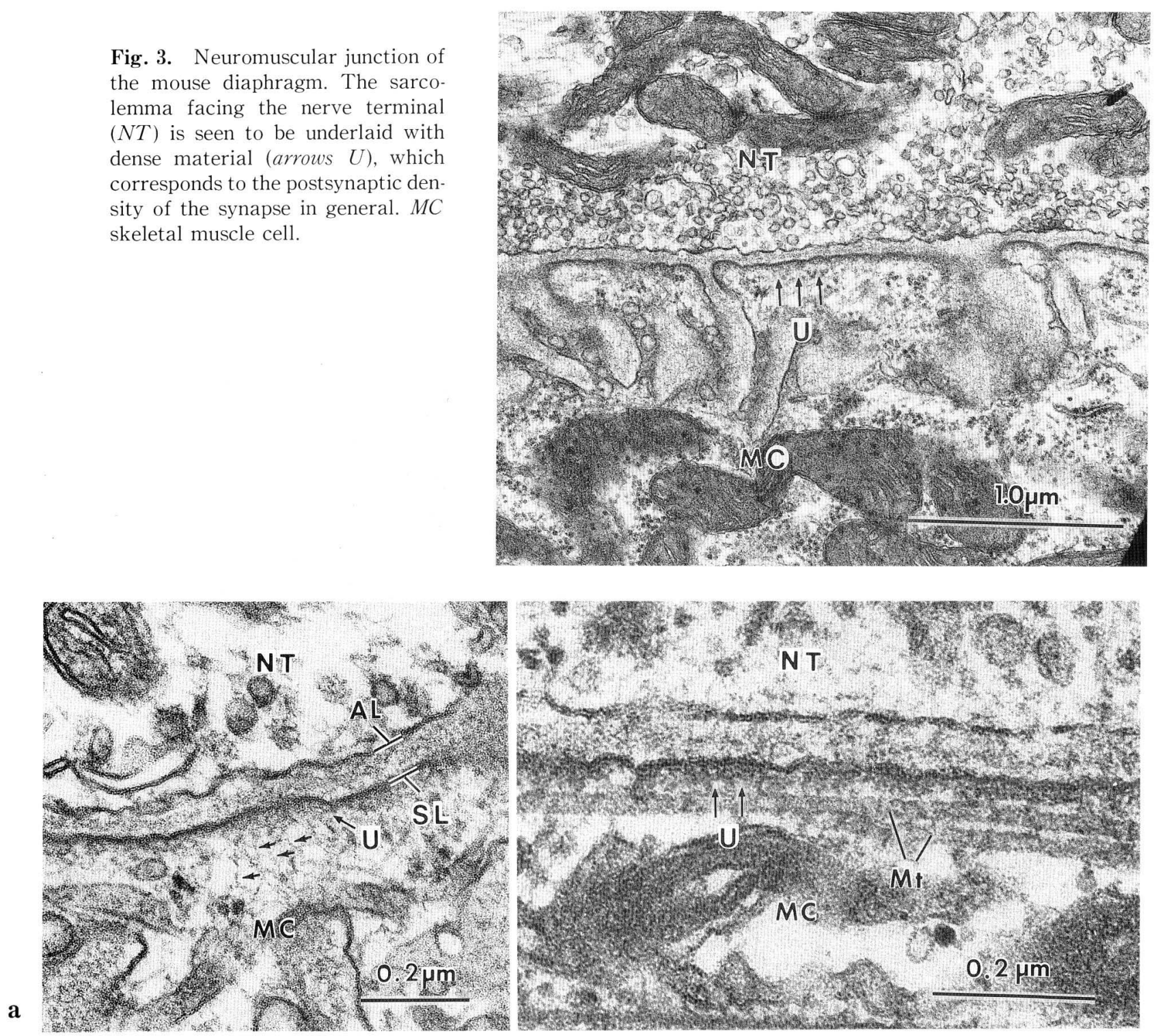

Fig. 4. Neuromuscular junction. a. Postsynaptic densities (arrow $U$ ) are seen as applied to the sarcolemma $(S L)$, to which fine filaments are attached through the density (arrows). NT nerve terminal, AL presynaptic membrane (axolemma), MC skeletal muscle cell. b. Developing neuromuscular junction in the posterior latissimus dorsi muscle from an 18-day chick embryo. Note the close association of the postsynaptic density (arrows $U$ ) with underlying microtubules $(M t)$. 

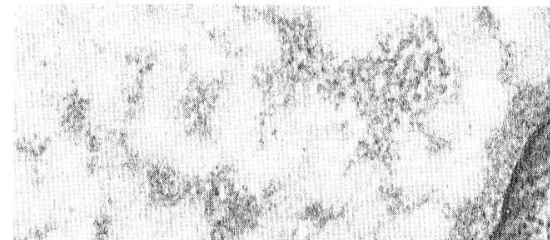

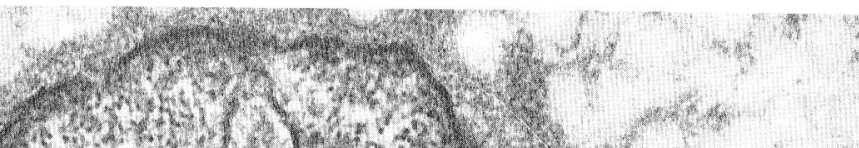
- 1 H.

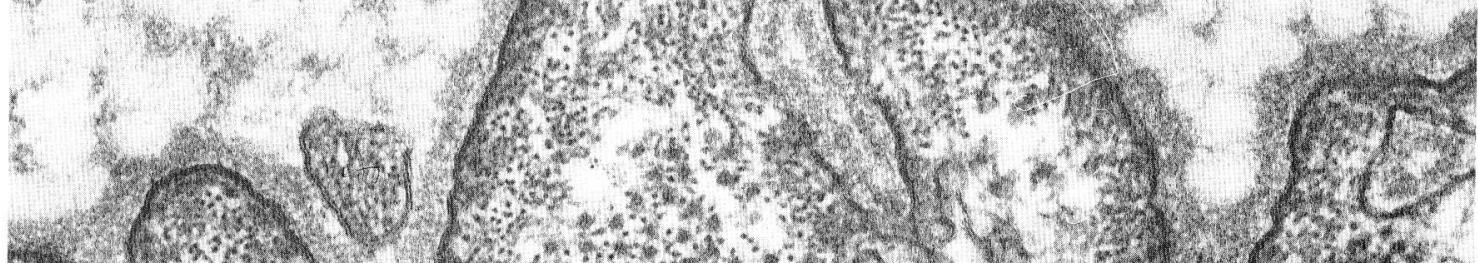

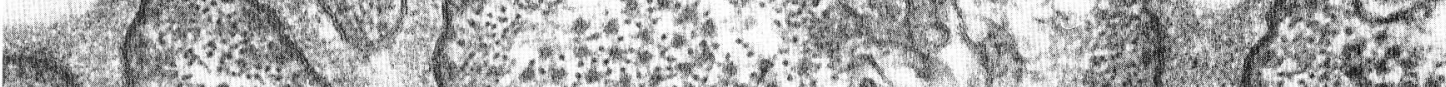

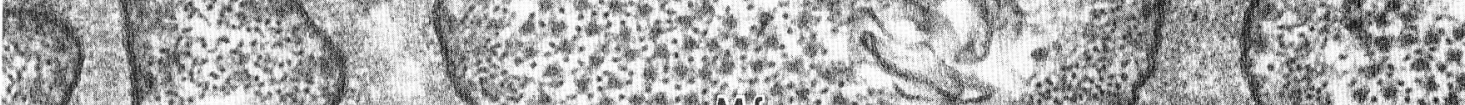

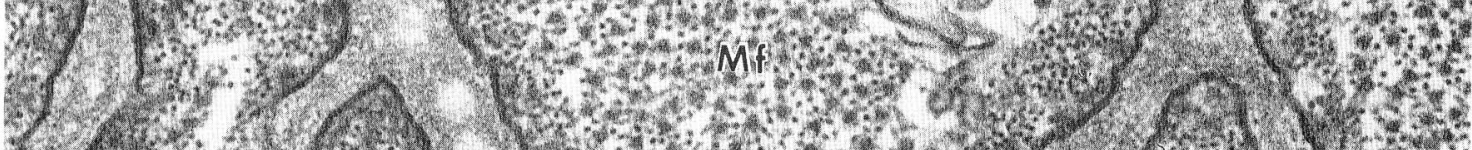

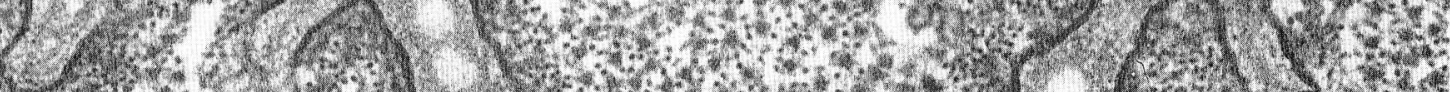

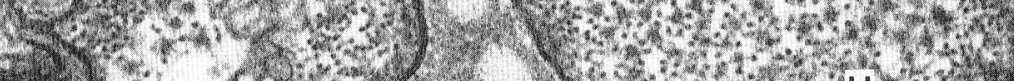

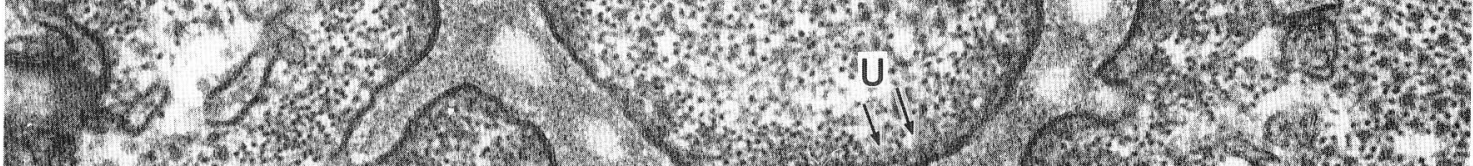

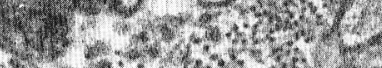

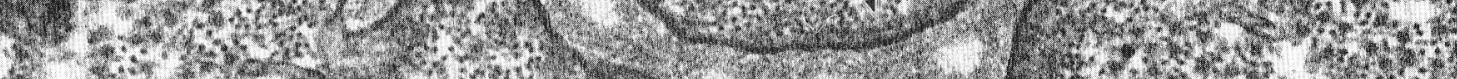

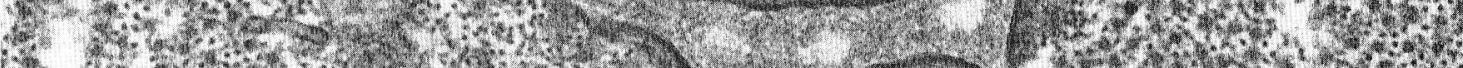

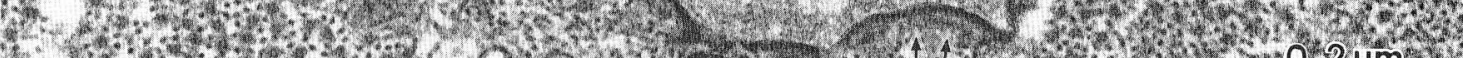

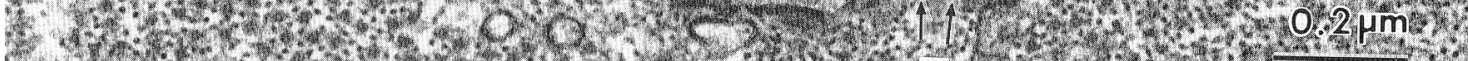

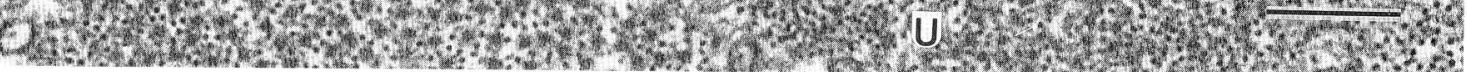
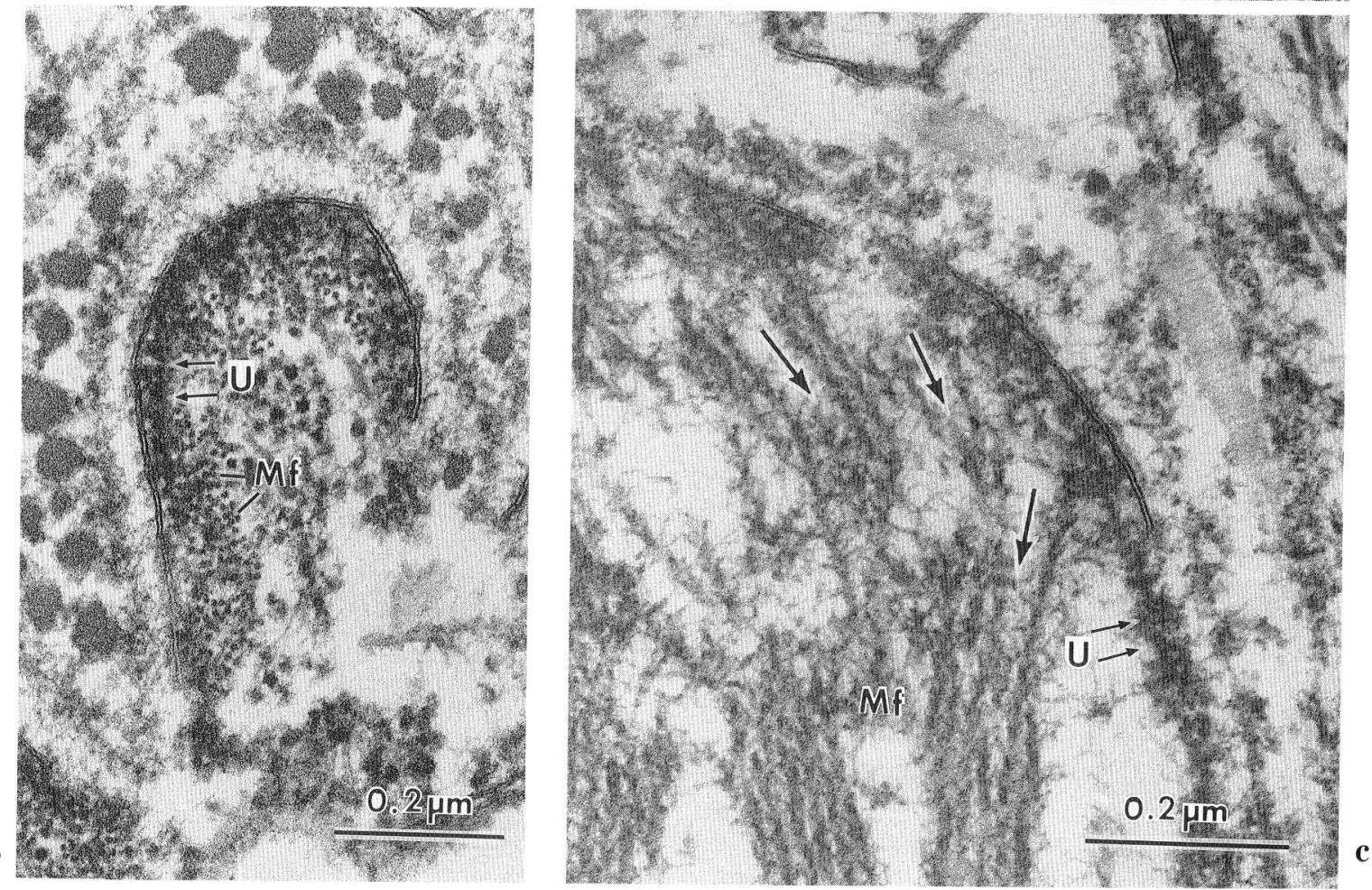

Fig. 5. Legend on the opposite page. 
During the development of the neuromuscular junction, the earliest sign of the post-synaptic membrane is the undercoat formation with concomitant cytochemical demonstration of acetylcholine esterase activity (Kelly and ZACKS, 1969; Atsumi, 1977; WELDON and COHEN, 1979). Interestingly, microtubules are closely associated with post-synaptic density in developing neuromuscular junctions of chick embryos (IsHikAwA et al., 1981) (Fig. 4b).

The pre-synaptic membranes in brain synapses are characterized by dense projections which form a haxagonal array to facilitate the exocytosis of synaptic vesicles (AKERT et al., 1972; HEUSER and
REESE, 1973). At neuromuscular junctions, the presynaptic densities are seen as multiple bars aligned in parallel, each forming active zones (CECCARELLI et al., 1973). Individual active zones have been shown by freeze fracture to be belt-like bumps of the membrane with paired arrays of intramembranous particles on either side of the membrane bump (HEUSER et al., 1974).

\section{Plasmalemmal undercoats in muscle cells}

Plasmalemmal undercoats are also seen in areas where cytoplasmic fibrous structures are attached.
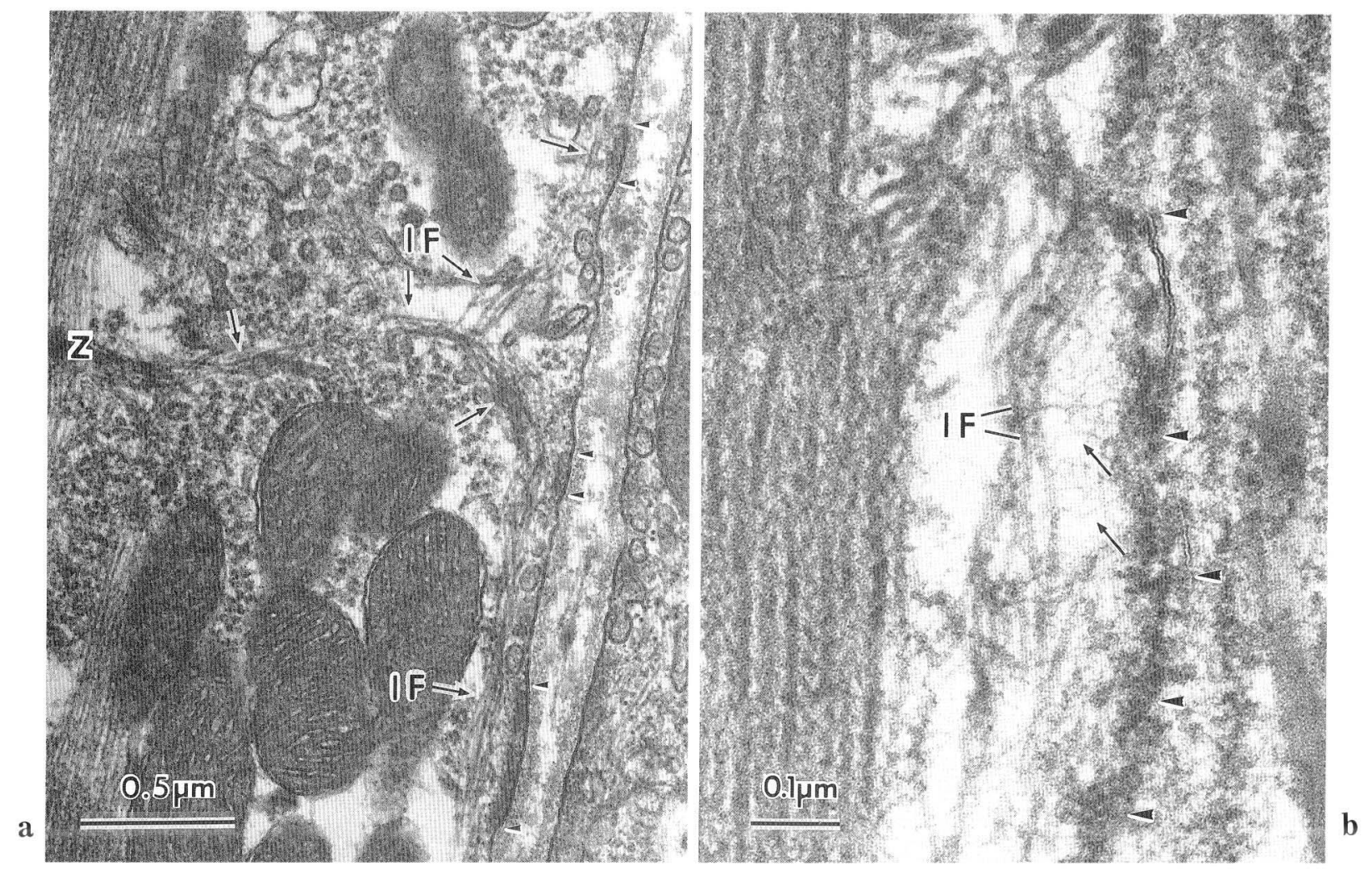

Fig. 6. Longitudinal section of muscle fibers in the mouse diaphragm. a. Bundles of intermediate filaments (arrows $I F$ ) run from the $Z$ disk $(Z)$ to the fiber surface, where they are closely associated with the dense patches (arrowheads) underlying the sarcolemma. b. In a Triton-treated muscle cell the close association between the intermediate filaments $(I F)$ and the dense patches (arrowheads) can be clearly seen. Note very fine filaments (arrows) connecting the two structures.

Fig. 5. Transverse section of a myotendinous junction in the mouse diaphragm. a. Myofibrils $(M f)$ attach to the sarcolemma through the dense material, which shows a layered organization beneath the membrane (arrows $U$ ). b Such undercoats can more clearly be seen in Triton X-100 treated muscle cells (arrows $U$ ). Actin filaments of the myofibrils $(M f)$ fail to penetrate the undercoat. The trilamellar structure of the sarcolemma are well preserved at the attachment site. c. Heavy meromyosin decoration after Triton treatment. Actin filaments of the terminal sarcomeres $(M f)$ attach to the undercoat (arrows $U$ ) with the arrowheads pointing away from the sarcolemma (large arrows). 
Typical examples of attachment of actin filaments to the plasmalemma can be found in striated and smooth muscle cells. The problem of how myofibrils are connected with the plasmalemma (or sarcolemma) may be common to many other types of cells, as the actin-membrane association is universally observed. At the ends of skeletal muscle cells, myofibrils anchor to the sarcolemma (NAKAO, 1976; TROTTER et al., 1983; ISHIKAWA, 1983). The undercoat structure at the attachment site clearly shows a layered organization: an electron-dense layer parallel to the sarcolemma and a less dense layer of perpendicular substruc- tures between the dense layer and the sarcolemma (FujIMAKI et al., 1985) (Fig. 5a). Actin filaments of the terminal sarcomere appear to be connected to the dense layer without penetrating it (ISHIKAWA et al., 1981). After extraction with Triton-X 100 the structural relation between the dense layer and actin filaments is more clearly demonstrated (Fig. 5b). The layered structure of the undercoat is not disrupted even after prolonged Triton extraction. Interestingly, the trilamellar structure of the sarcolemma at these sites also persists, suggesting that the membrane itself is indeed structurally specialized. More recent-

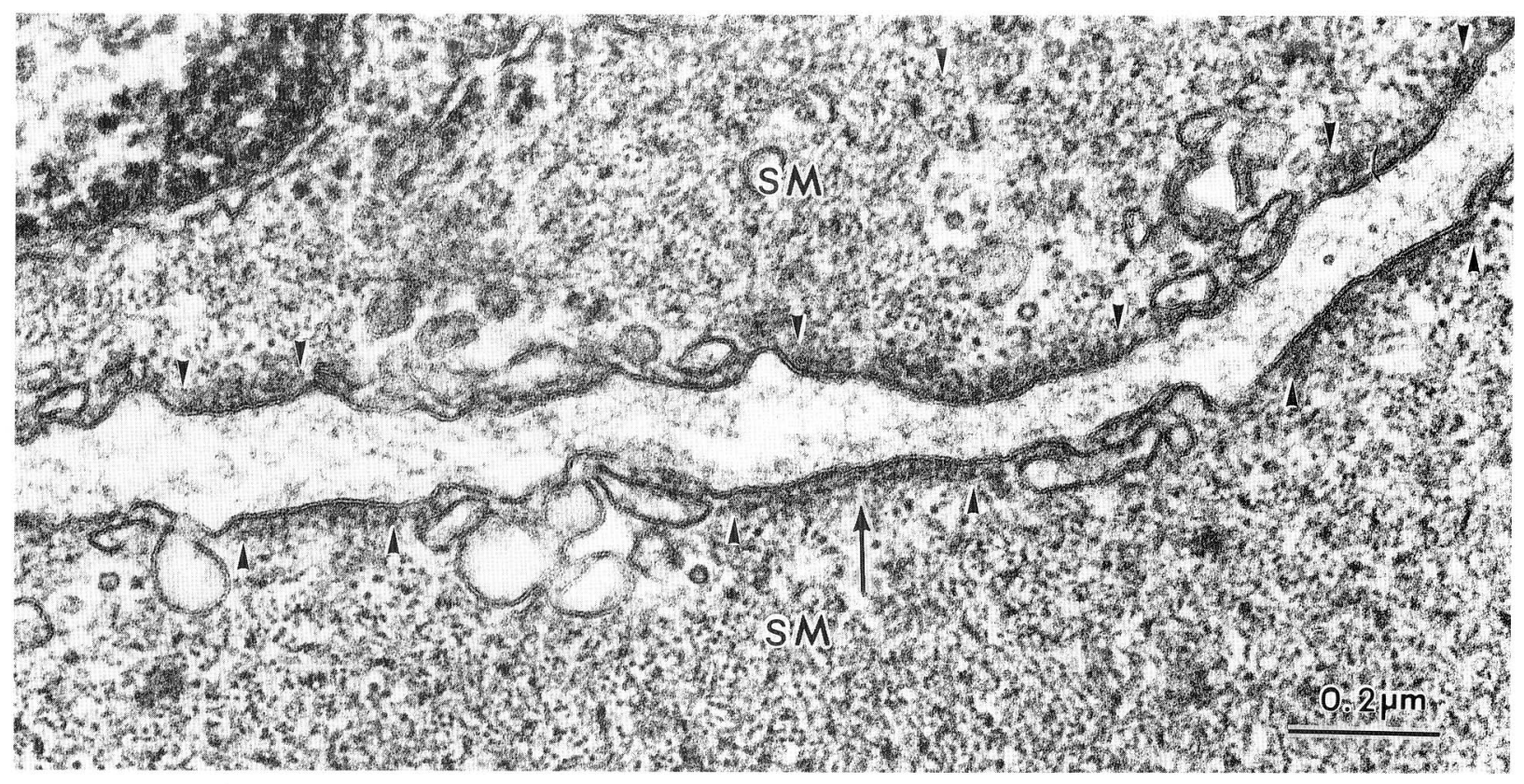

Fig. 7. Smooth muscle cells from the guinea-pig ureter. Muscle cells (SM) possess many dense plaques (arrowheads) along the cell surface. The dense plaques show a layer organization (arrow) similar to the undercoat structures in other types of cells.

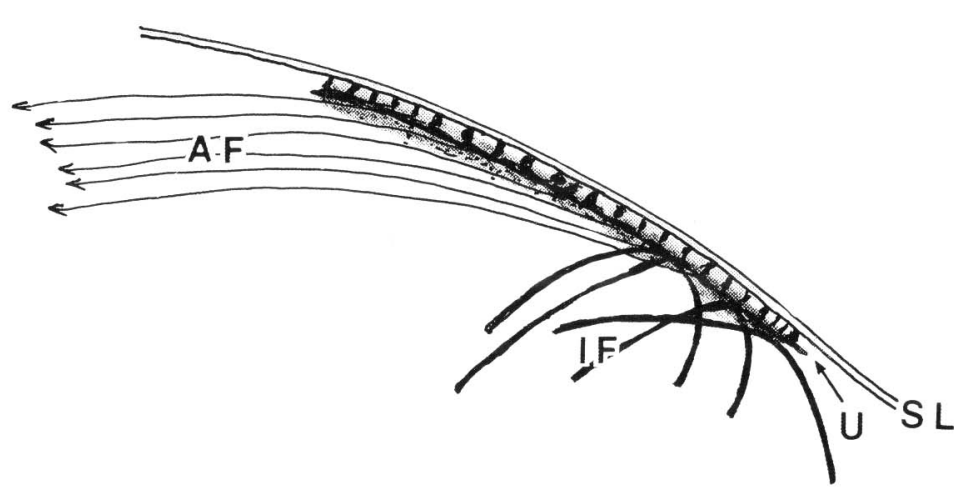

Fig. 8. Schematic illustration of the association of filamentous components with the dense plaques in smooth muscle cells. Some dense plaques provide attachment sites for actin myofilament $(A F)$ with uniform polarity (i. e., arrowheads with heavy meromyosin pointing away from the sarcolemma), while others are involved in the attachment of intermediate filaments (IF) to the sarcolemma ( $S L)$. Both types of dense plaques (arrow $U$ ) may adjoin each other. 
ly, a characteristic intramembranous organization of the sarcolemma at the sites of myotendinous junctions has been observed (BARTELS, 1987). When treated with heavy meromyosin after Triton extraction, actin filaments of the terminal sarcomere are decorated with arrowheads pointing away from the sarcolemma (Fig. 5c).

In addition, another type of domain with similar undercoat structures are discerned, scattered along the sarcolemma with which intermediate filaments are associated (FUJIMAKI et al., 1986). Intermediate filaments, which run transversely at the level of the $Z$ disc, appear to attach laterally to the undercoat (Fig. 6a). At high magnification many fine filamentous structures $(2-3 \mathrm{~nm})$ can be found to connect intermediate filaments together and also with the undercoat (Fig. 6b). Such intermediate filament-associated undercoats are located next to and even continuous with the myofibril-associated ones at the end of the muscle cell (FUJIMAKI et al., 1986). A similar situation occurs in smooth muscle cells (Fig. 7), in which two distinct domains with similar undercoat structures can be distinguished, one for actin filaments and the other for intermediate filaments (Tsukita et al., 1983) (Fig. 8). In cardiac muscle cells, myofibrils are anchored to the fascia adherens of the intercalated disc (see Fig. 10b), while intermediate filaments are connected with desmosomes (see Fig. 10c).

\section{Plasmalemmal undercoats for cell adhesion}

Actin filaments tend to form parallel bundles in many types of non-muscle cells (ISHIKAWA, 1979; BUCKLEY, 1981). In tissue cells, actin bundles are firmly anchored to the plasmalemma. Such anchoring domains of the plasmalemma are also characterized by the occurrence of an undercoat structure similar to that of muscle cells (Fig. 9). Such undercoats are also found at the attachment sites for stress fibers at focal contacts of cultured cells. Similar situations are found in the zonula adherens of epithelial cells (Fig. 10). Vinculin, talin, alpha-actinin and some other proteins are immunohistochemically localized in these domains (GEIGER, 1983; Burridge, 1983; MAN . GEAT and BURRIDGE, 1984). In addition, the plasmalemma in these domains seems to be specialized. At focal contacts, stress fibers form transmembrane complexes with the extracellular matrix, especially fibronectin (Fig. 9a). In other words, extracellular fibronectin molecules seem to communicate through some transmembrane linkage with intracellular actin filaments (SINGER, 1979, 1982; HYNES, 1981). Unique rectangular arrays of intramembranous particles have been found by freeze fracture at the zonula
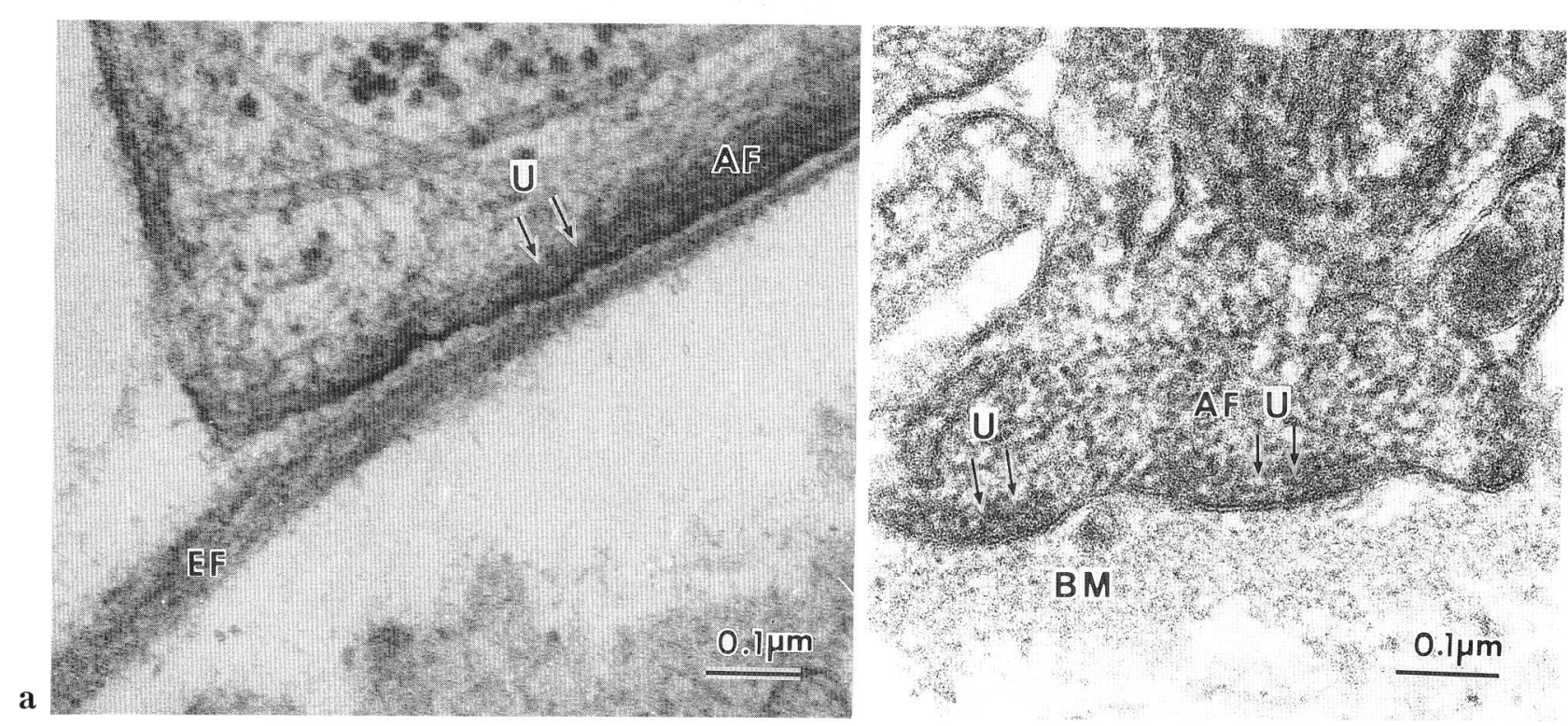

Fig. 9. Dense plaques underlying the plasmalemma in non-muscle cells. a. Dense plaque at the attachment site for a stress fiber in a cultured cartilage cell. An actin filament bundle $(A F)$ terminates obliquely in the dense plaque (arrows $U$ ) applied to the inner surface of the plasmalemma, from which an extracellular matrix fibril (probably fibronectin) arises $(E F)$. b. Dense plaques at the base of an epithelial cell of the mouse renal proximal tubule. Bundles of actin filaments $(A F)$ are attached to the plasmalemma through the dense plaques (arrows $U$ ). $B M$ basement membrane. 


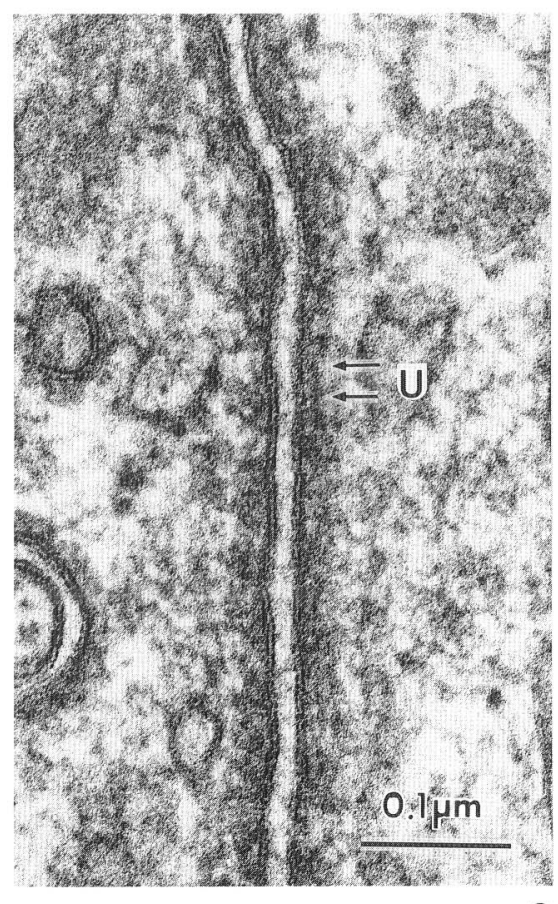

a

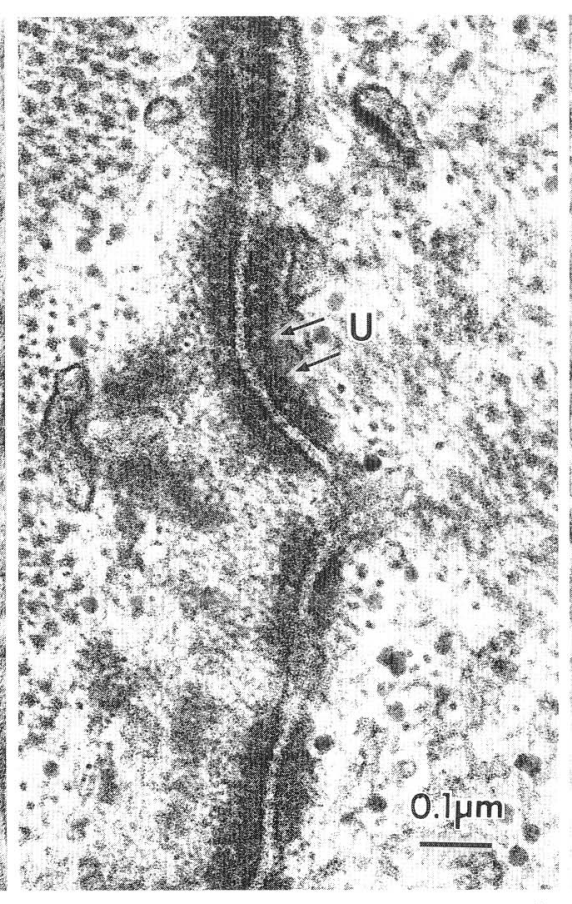

b

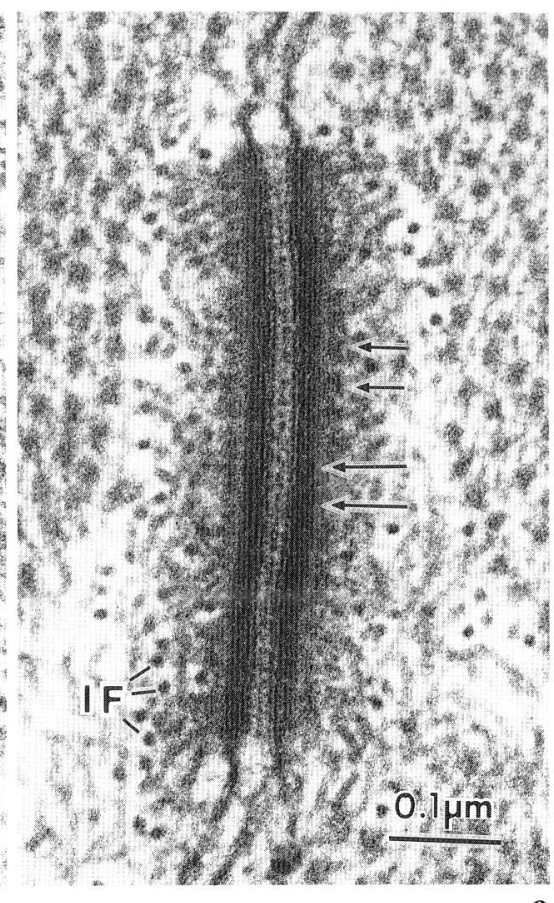

c

Fig. 10. Dense plaques at intercellular junctions. a. Zonula adherens in epithelial cells of the mouse renal proximal tubule. Dense materials (arrows $U$ ) are applied in a layered organization to the cytoplasmic surface of the plasmalemma. Actin filaments are preferentially associated with this type of the adherens junction. b. Fascia adherens in cardiac muscle cells of the rabbit conducting system. Thick electron-dense layers are seen on the cytoplasmic surface of the apposed plasmalemma, where myofibrils are attached. c. Macula adherens (desmosome) in a cardiac muscle cell of the rabbit. The desmosome is revealed to be constructed of several layers. More closely applied to the cytoplasmic surface of the plasmalemma is a very dense plaque (long arrows), which is further underlaid with a less dense layer (short arrows). Intermediate filaments (IF) attach exclusively to the desmosome.

adherens in the guinea-pig organs of Corti (HAMA and SAITO, 1976).

As mentioned above, the adherens junctions are underlaid with the plasmalemmal undercoats (Fig. 10). In this connection, the desmosome and hemidesmosome can also be considered to be another special form of the plasmalemmal undercoat. An electron-dense thick plaque is closely applied to each cytoplasmic aspect of the apposed plasmalemma (Fig. 10c). In cells having desmosomes, intermediate filaments attach exclusively to the desmosome, forming loops for a lateral association (KELLY, 1966; RAYNS et al., 1969; Staehelin, 1974). Fine filamentous structures are seen to link intermediate filaments to the plaque (see also Tsukita and Tsukita, 1985). In astroglia, desmosome-like junctions are found. This intercellular junction is also underlaid with a prominent layer of dense material, with which intermediate glial filaments are closely associated (Fig. 11b, c). At the end-feet of the astrocyte, the undercoats are developed on the plasmalemma facing the pia mater and blood vessels (Fig. 11a). Gap junctions in certain cell types such as cardiac and smooth muscle cells may possess ambiguous undercoats (Fig. 12), whereas those in many other types of cells do not show any such underlying structures.

\section{Plasmalemmal undercoats in some selected cells}

Undercoat structures have been demonstrated in the epithelial cells of the macula densa of renal distal tubules (YAMADA, 1975), salivary glands of the bat (YOHRO and KAMIYA, 1971) and various organs of certain insects (GUPTA and BERRIDGE, 1966; BERRIDGE and Oschman, 1969; Oschman and BerRidge, 1970), which are thought to be involved in the transport of ions and water. In epithelial cells of the macula densa, a layer of electron-dense material is closely applied to the plasmalemma of the luminal surface including finger-like processes (Fig. 13). Another 


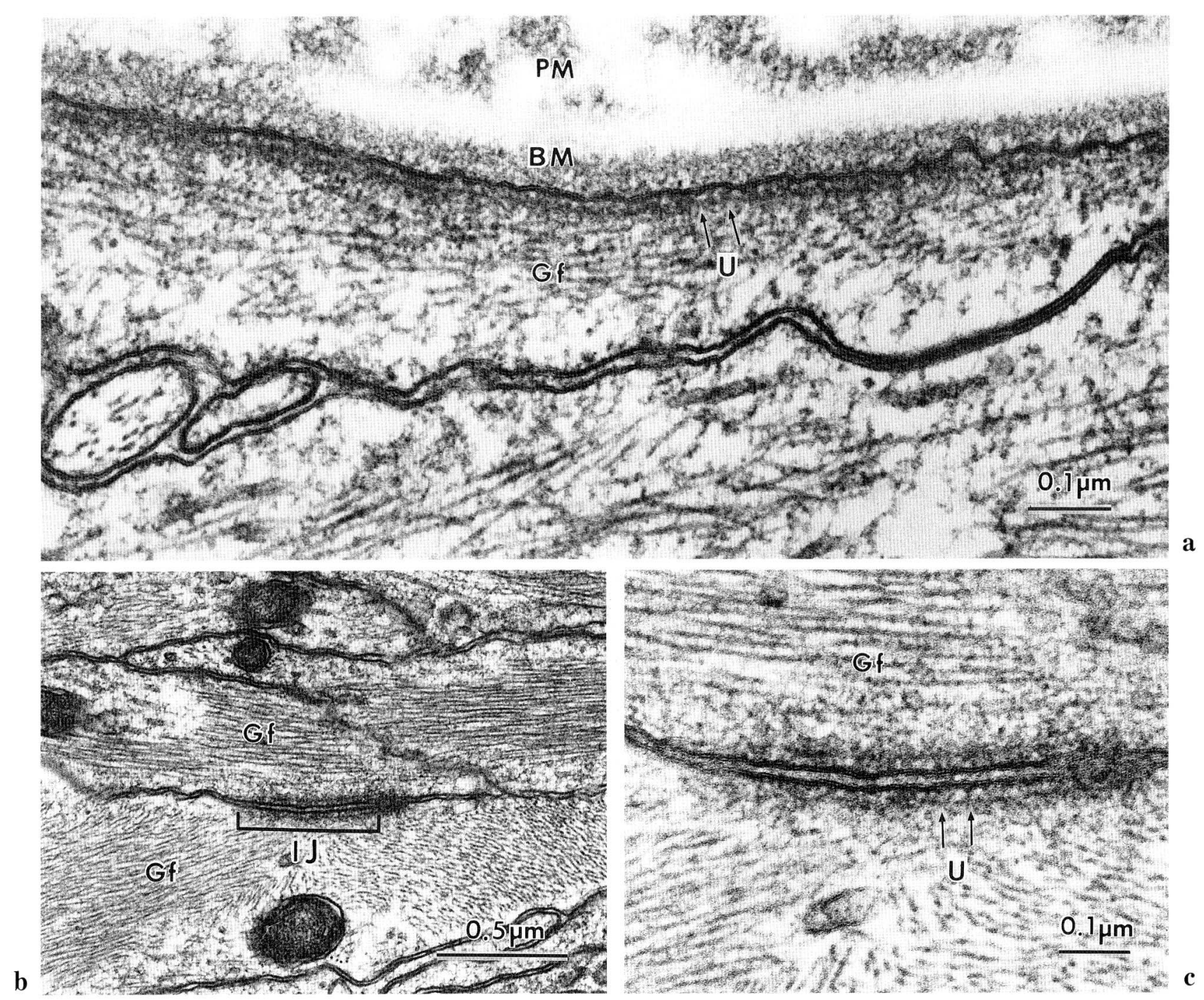

Fig. 11. Undercoat structures in astroglia of the monkey. a. Endfoot of the astrocyte process. Prominent undercoats (arrows $U$ ) are found in a larger expanse on the plasmalemma facing the pia mater $(P M)$. Glial filaments $(G f)$ appear to be closely associated with the undercoat. $B M$ basement membrane. b. Intercellular junction $(I J)$ seen between astrocyte processes, which are characterized by the occurrence of intermediate-sized glial filaments $(G f)$. c. Higher magnification of the intercellular junction seen in Figure b. The layered organization of the undercoat can be clearly resolved (arrows $U$ ) as a parallel layer about $20 \mathrm{~nm}$ apart from the plasmalemma with a layer of interconnecting perpendicular components. Compare with the undercoat at the astroglial endfoot (a).

example is the undercoat seen in the ruffled border of osteoclasts (KALLIO et al., 1971; KANO et al., 1986).

Microtubules are closely associated with the plasmalemma in some types of cells. Typical examples are found in various vertebrate spermatids (FAW CETT et al., 1971) (Fig. 14), in insect epidermal tendon cells (Auber, 1963; Caveney, 1969), in crab tendon cells (K. КАтон and IshikaWA, unpublished data) (Fig. 15), and in pilar cells of the inner ear (HAMA and
SAITO, 1976), in which a number of microtubules are arranged parallel to the cell axis and are anchored to the plasmalemma at either one or both ends in an end-on fashion. At these attachment sites are always found the undercoat structures, which appear to mediate the association of microtubules with the plasmalemma.

The bristle coats of coated pits and vesicles may also be regarded as another form of the plasmalem- 
mal undercoat, though coated vesicles are also formed from the Golgi membranes. The net is constructed of clathrin (PEARSE, 1976) forming triskelion units (UNGEWICKELL and BRANTON, 1981; KIRCHHAUSEN and HARRISON, 1981). The binding of ligands to specific receptors induces the assembly of the clathrin coat on the cytoplasmic surface of the plasmalemma, and vesicles are then formed through a pinching-off process (ANDERSON et al., 1977). The aggregation of intramembranous particles is also observed at the coated pits (IsHimURA et al., 1980).

In conclusion, virtually all the cell types possess plasmalemmal domains which are underlaid with an electron-dense material as revealed by thin-section electron microscopy. Such undercoat structures vary in appearance among different types of cells and different regions of the plasmalemma. However, there are some common morphological features as described above. Such features may be used as morphological criteria for defining the plasmalemmal undercoat.

\section{FUNCTIONAL SIGNIFICANCES OF THE PLASMALEMMAL UNDERCOAT}

Based on the distribution pattern of the plasmalem- mal undercoats and their association with other structures in many types of cells, we may speculate on its functional significance. Indeed, these structures are often found in close relation to the localization of certain specific functions of the plasmalemma. Thus, accumulated data suggest that the plasmalemmal undercoat may have three distinct but mutually related functions: 1) mechanical support for the plasmalemma, 2) the regulation of distribution of integral membrane proteins, and 3) the attachment of cytoskeletal fibrous components. It should be stressed that the plasmalemmal undercoat primarily provides a structural support for the membrane.

\section{Mechanical support}

The undercoats appear to mechanically support limited or whole areas of the plasmalemma, even if this function is not principal for these undercoats. There are many instances in which the occurrence of the undercoats can be considered to relate to the observed rigidity, strength and elasticity of the membranes, thus serving as a so-called membrane skeleton (LuX, 1979).

In human erythrocytes, the spectrin-actin network is the only formed structure for a candidate to play some role in determination of cell shape while retain-

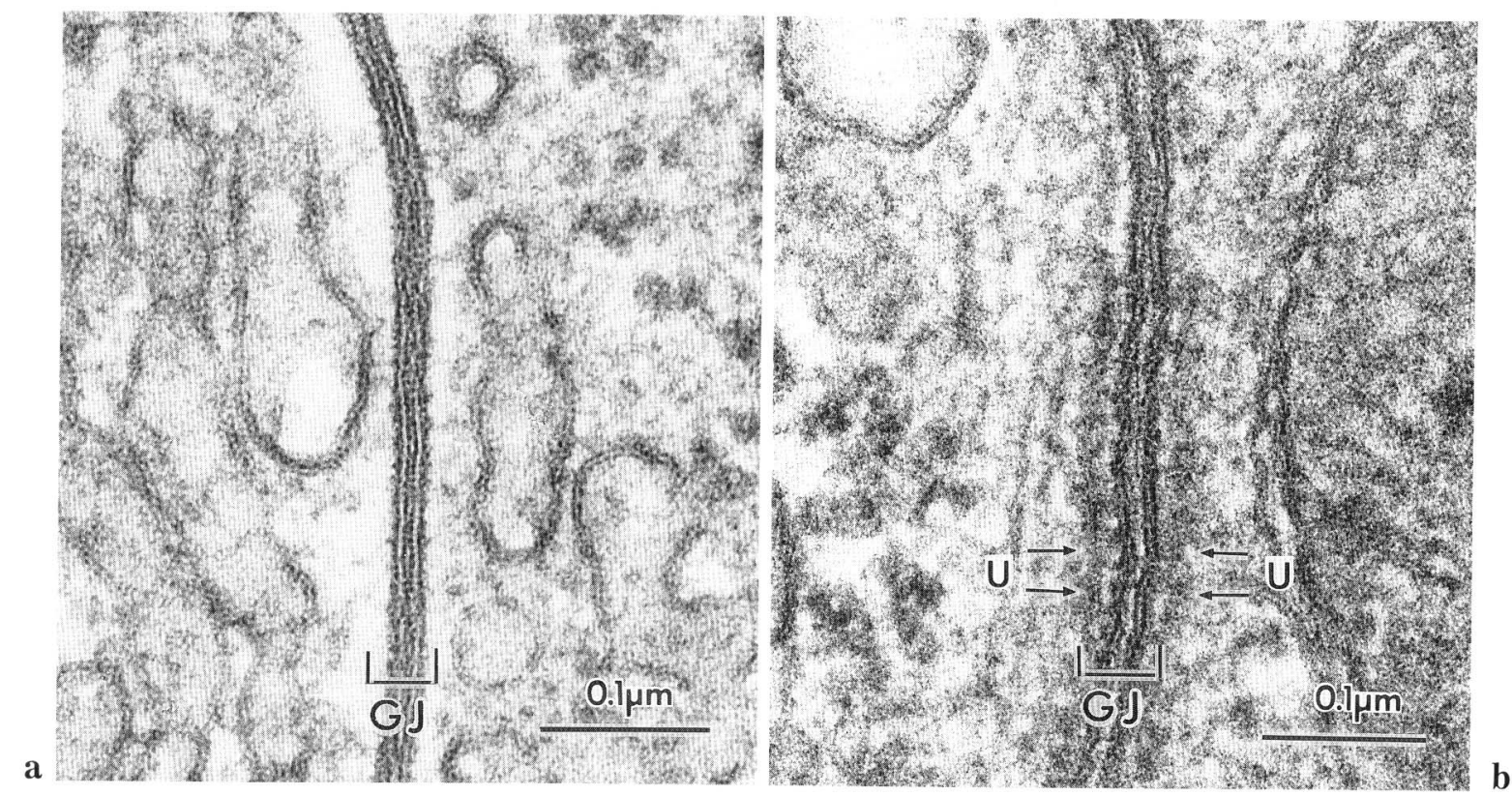

Fig. 12. Gap junctions in different cell types. a. In interstitial cells of the mouse testis, no undercoat structures are visible on the cytoplasmic surface of the plasmalemma at the gap junctions $(G J)$. b. In smooth muscle cells of the guinea-pig ureter, the gap junctions $(G J)$ are seen to be undercoated with electron-dense materials (arrows $U$ ). 


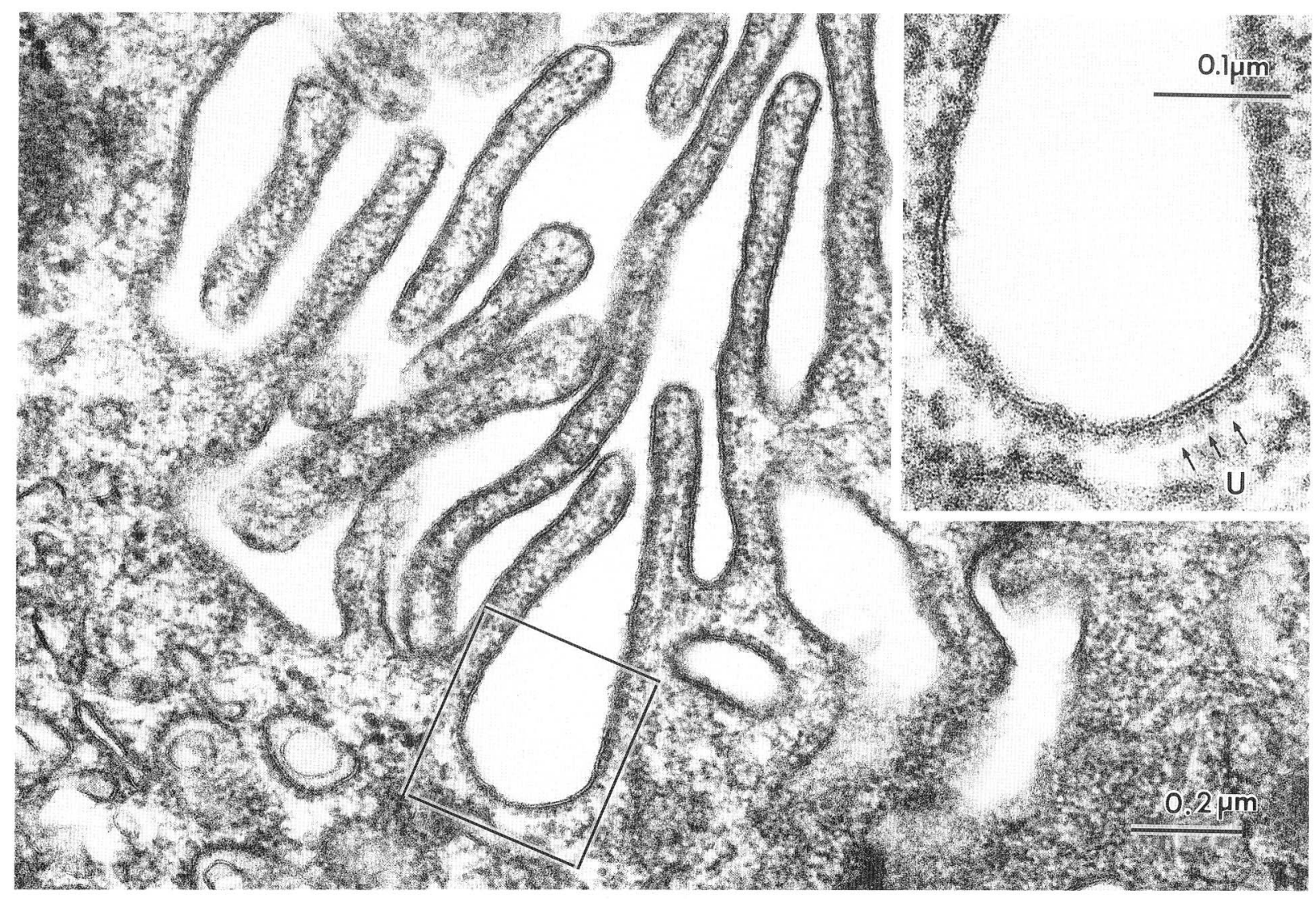

Fig. 13. Undercoat structure in an epithelial cell of the macula densa of the mouse renal distal tubule. The plasmalemma of the luminal surface including finger-like projections is characterized by electron-dense materials applied to its cytoplasmic surface. Inset. Higher magnification of the area marked by the square. The bristle-like undercoat can be clearly visualized (arrows $U$ ).

ing their deformability and elasticity (Lux, 1979; Branton et al., 1981; MARCHESI, 1983). There is no reasonable explanation as to how their biconcave cell shape is formed, though reversible alterations in shape can be induced in Triton-treated erythrocyte ghosts (JimBU et al., 1984). In this connection, the recent demonstration of an authentic myosin may deserve attention, as it might constitute an actomyosin contractile system with actin beneath the plasmalemma (FowleR, 1986).

Mechanical supports are also provided for the plasmalemma at the attachment sites of cytoplasmic fibrous components such as myofibrils, stress fibers, intermediate filaments, and microtubules. It seems reasonable to consider that the plasmalemma at these domains requires the mechanical support given by the undercoat in order to anchor the fibrous components and transmit mechanical forces across the plasmalemma. Some rigidity has also been suggested in the nodes of Ranvier of myelinated axons and in the postsynaptic membranes, where the undercoats are developed (Tsukita and IsHikawa, 1980).

\section{Regulation of integral membrane protein distri- bution}

Mechanical support for the membrane can be established through the association between the undercoat and integral membrane proteins. These proteins could be functional, such as channels and receptors. With this the distribution of integral membrane proteins may be regulated through the membraneundercoat association. This idea could explain observations that the localization of specific channels and receptors to certain areas of the plasmalemma coincides with that of the undercoat. For example, sodium channels are concentrated at the initial segments and the nodes of Ranvier of myelinated axons, and acetylcholine receptors are localized on the post-synaptic membrane of the neuromuscular junc- 

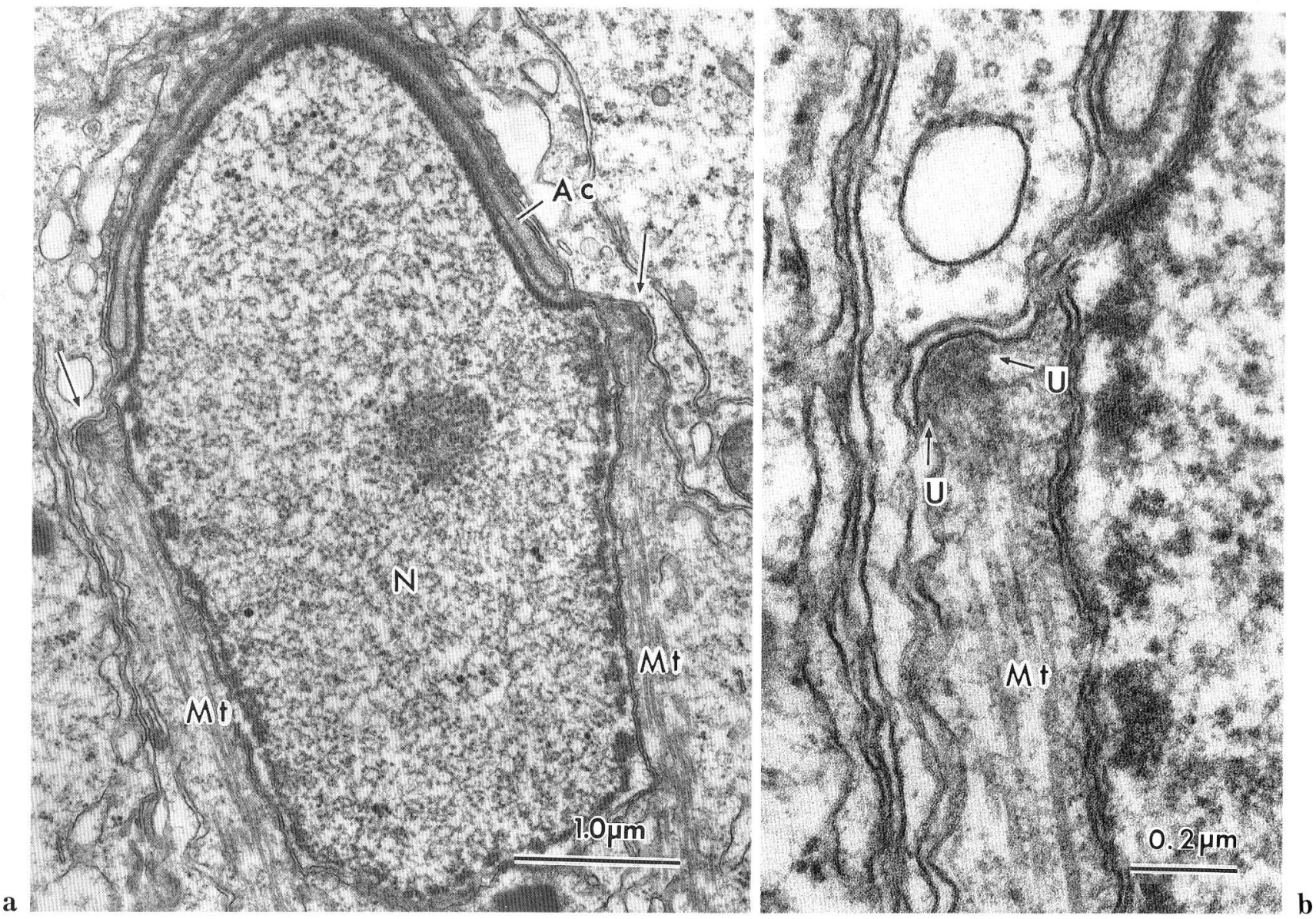

Fig. 14. Spermatid of the mouse testis. a. A parallel bundle of microtubules surrounds the nucleus $(N)$ forming a manchette $(M t)$. The microtubule manchette attaches to the plasmalemma at the nuclear ring (arrows). Ac acrosome. b. Higher magnification shows that microtubules $(M t)$ terminate on the plasmalemma through the dense materials (arrows $U$ ) at the nuclear ring.

tion. The undercoat thus seems to prevent the diffusion of such functional proteins.

In erythrocyte membranes, the spectrin-actin network has been shown to be connected to the membrane through an anchoring protein, ankyrin (STECK, 1974; MARCHESI et al., 1976). Ankyrin can link spectrin and band 3 protein, which is believed to function as an anionic channel (STECK, 1978). Although only a fraction of band 3 proteins attach to the spectrinactin network, the distribution of band 3 proteins as a whole is regulated (STECK, 1974; MARCHESI et al., 1976; Cohen, 1983). Freeze-fracture studies indicate that the intramembranous particles, which are believed to represent the glycophorin-band $3 \mathrm{com}$ plexes, are restrained from lateral movement in the intact human erythrocyte membrane (ELGSAETER and BRANTON, 1974) (see Fig. 2c), whereas they can be aggregated in the spectrin-extracted membrane (ELG
SAETER et al., 1976). For the erythrocyte functions, a rather uniformly dispersed distribution of the channels all over the cell surface is more favorable than a local aggregation. As such, actin-plasmalemma associations in general are believed to be important to the distribution of cell-surface proteins such as receptors and channels (GEIGER, 1983).

Similar situations may be found in the macula densa of the renal distal tubule and in the ruffled border of osteoclasts. Cells apparently utilize the undercoats to localize the integral membrane proteins, resulting in the formation of functional domains. The clathrin coat is another example of the undercoat localizing specific receptors, here for receptor-mediated endocytosis (PEARSE and BRETS. CHER, 1981; FINE and OCKLEFord, 1984). The assembly of clathrin coats in response to ligand binding may serve as a model system for elucidating the process 


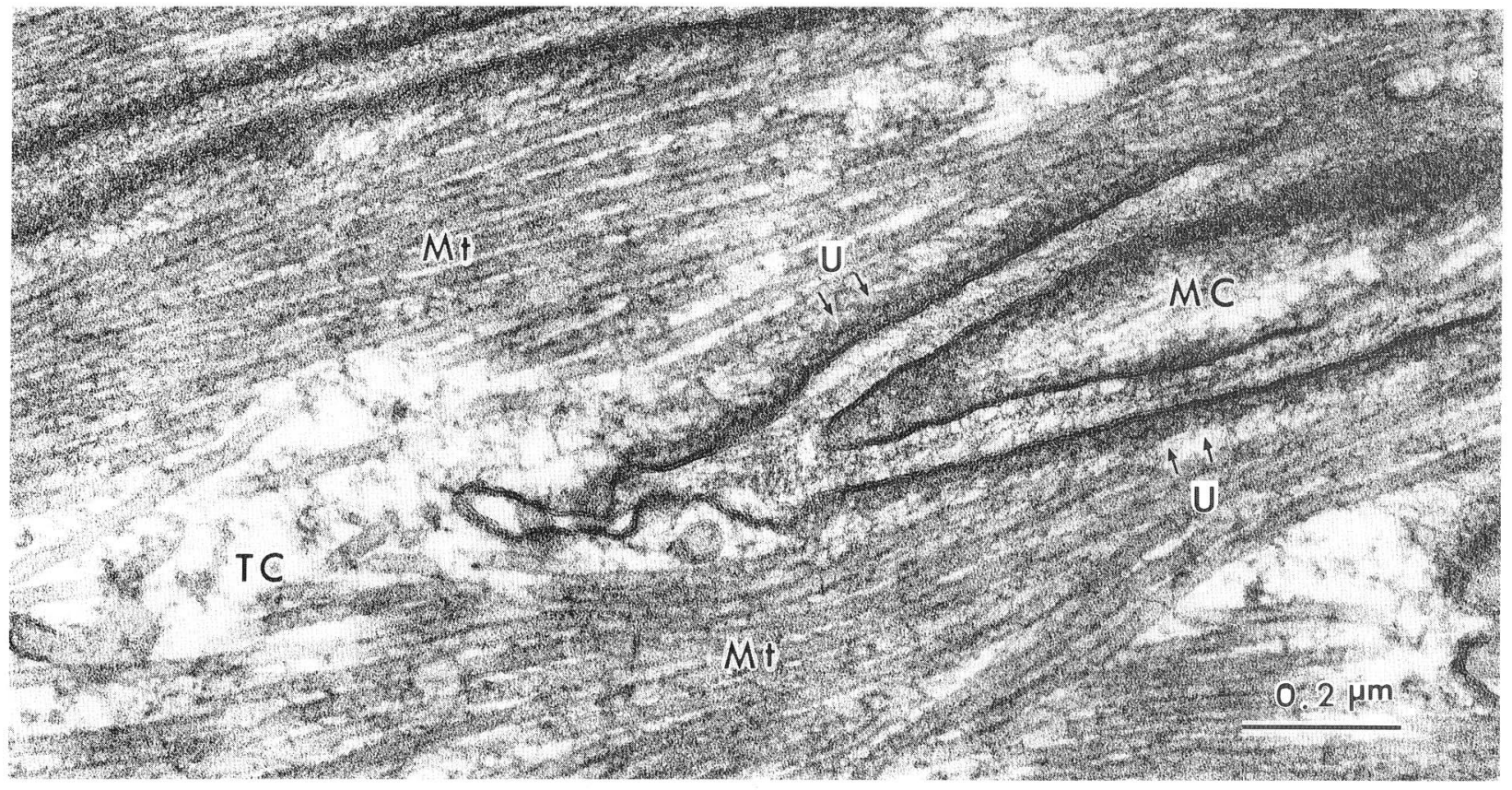

Fig. 15. Tendon cells of a crab leg. Numerous microtubules $(M t)$ run parallel to the long axis of the tendon cell (TC) and attach to the plasmalemma at both ends. The plasmalemma at the attachment sites is characterized by prominent undercoat structures (arrows $U$ ), to which microtubules appear to be tightly connected by very fine filaments. $M C$ muscle cell.

of localization of functional proteins that occurs concomitantly with the undercoat formation in general.

\section{Attachment of cytoskeletal fibrous components}

The plasmalemmal undercoat may provide the attachment sites for cytoskeletal fibrous components, such as actin filments, intermediate filaments and $\mathrm{mi}$ crotubules (ISHIKAWA, 1979). At the attachment sites the plasmalemma definitely needs some mechanical support. Many studies have elucidated the molecular architecture of the attachment devices for actin filaments at cell-to-cell and cell-to-substrate adhesions. Various actin-binding proteins such as vinculin, talin and alpha-actinin are co-localized at sites of actin-plasmalemma association and cell adhesion and are believed to be involved in the attachment (GEIGER, 1983; Mangeat and Burridge, 1984). However, the details of their participation in these attachments have not yet been clarified.

Actin filaments are always polarized with arrowheads pointing away from the membrane (ISHIKAWA et al., 1969; Small et al., 1978). Thus, the plasmalemmal undercoat may also serve as the organizing center for actin filaments. The polarity of actin filaments may be regulated, possibly by a capping protein within the undercoat. The simplest mode of actin attachment to the membrane is seen in the erythrocyte (BRANTON et al., 1981). Besides spectrinankyrin-band 3 protein association, actin may be connected with glycophorin within the membrane via band 4.1 protein. Short actin filaments are parts of the undercoat which are connected to the membrane. Upon the addition of muscle actin, the pre-existing actin filaments can elongate to extend from the membrane (Tsukita et al., 1984). In the presence of cytochalasin B, a barbed-end capping agent, such elongated filaments generally oriented with arrowheads pointing away from the membrane.

As mentioned above, actin filaments appear to be anchored to the membrane via the undercoat. The possibility can not be excluded that actin may be a constituent of the undercoat, as seen in the erythrocyte membrane. It is not clear as to how close actin filamments extend toward the membrane proper. Actin filaments could be associated with the membrane in a simple, rather direct manner without any involvement of the of the specialized undercoat (POL LARD and WEIHING, 1974; SMALL, 1981). The details of such association are not easily visualized, and therefore are not discussed here. 
Intermediate filaments also attach to the plasmalemma via the undercoats, the most typical example being the desmosome with which intermediate filaments are exclusively associated. They appear to be linked to the dense plaque with fine filamentous structures in a lateral association forming loops. The plaque could mechanically strengthen the apposed plasmalemma and concurrently provide an attachment site for intermediate filaments, which extend deep inside the cell. Similar situations can be found in skeletal and smooth muscle cells. The undercoat forms the scaffold on the plasmalemma for intermediate filaments, which participate in the spatial arrangement of myofibrils within a muscle cell (LAZARIDES, 1980). Interestingly, spectrin has been shown in vitro to bind to intermediate filaments, suggesting that spectrin may also link intermediate filaments to one another, to actin filaments, and to the plasmalemma (LANGLEY and COHEN, 1986), thus forming a higher hierarchy of cytoskeletal organization.

Microtubules may play an important role in the development and maintenance of cell shape in many types of cells. They are anchored to the plasmalemma in certain cell types. In vertebrate spermatids during spermiogenesis and in pilar cells of the mammalian inner ear, parallel bundles of microtubules are attached to the plasmalemma via the undercoats. In insect epidermal tendon cells, microtubules seem to transmit the pull to the membrane through their firm attachment to the undercoat. A typical example of the lateral association of microtubules with the plasmalemma is found in the developing neuromuscular junctions of the chick embryo. The post-synaptic density is further supported by the underlying microtubules. The transient occurrence of microtubules at the developing synapses may be of morphogenetic significance.

\section{REFERENCES}

Akert, K., K. Pfenninger, C. Sandri and H. Moor: Freeze-etching and cytochemistry of vesicles and membrane complexes in synapses of the central nervous system. In: (ed. by) G. D. PAppas and D. P. Purpura: Structure and function of synapses. Raven Press, New York, 1972 (p. 67-86).

Anderson, R. G. W., M. S. Brown and J. L. Goldstein : Role of the coated endocytic vesicle in the uptake of receptor-bound low density lipoprotein in human fibroblasts. Cell 10: 351-364 (1977).

Atsumi, S.: Development of neuromuscular junctions of fast and slow muscles in the chick embryo. A light and electron microscopic study. J. Neurocytol. 6: 691-709
(1977).

Auber, J. : Ultrastructure de la jonction myo-epidermique chez les Dipteres. J. Microsc. 2: 325-336 (1963).

BARTELS, H.: Intramembrane aspects of myotendinous and myomuscular junctions: A freeze-fracture study of the gill sac-muscle of the Atlantic hagfish, Myxine glutinosa. Anat. Rec. 218: 249-255 (1987).

BennetT, V.: The molecular basis for membranecytoskeleton association in human erythrocytes. J. Cell. Biochem. 18: 49-65 (1982).

Berridge, M. J. and J. L. Oschman: A structural basis for fluid secretion by Malpighian tubules. Tiss. Cell 1: 247-272 (1969).

Branton, D., C. M. Cohen and J. Tyler: Interaction of cytoskeletal proteins on the human erythrocyte membrane. Cell 24: 24-32 (1981).

BuCKLEY, I. K.: Fine-structural and related aspects of nonmuscle-cell motility. In: (ed. by) R. M. DowBEN and J. W. Shay: Cell and muscle motility, Vol. 1. Plenum Publishing Corp., New York, 1981 (p. 135-203).

BURRIDGE, K.: Studies on $\alpha$-actinin and vinculin: proteins of the adhesion plaque. In: Current topics in cellular anatomy. Alan R. Liss, Inc., New York, 1983 (p. 51-65).

Burridge, K., T. Kelly and P. H. Mangeat : Nonerythrocyte spectrins: actin-membrane attachment proteins occurring in many cell types. J. Cell Biol. 95: 478-486 (1982).

Byers, T. and D. Branton: Visualization of the protein associations in erythrocyte membrane skeleton. Proc. Nat. Acad. Sci. USA 82: 6153-6157 (1985).

Caveney, S.: Muscle attachment related to cuticle architecture in Apterygota. J. Cell Sci. 4: 541-559 (1969).

Ceccarelli, B., W. P. Hurbut and S. Mauro: Turnover of transmitter and synaptic vesicles at the frog neuromuscular junction. J. Cell Biol. 57: 499-524 (1973).

Chan-Palay, V.: The tripartite structure of the undercoat in initial segments of Purkinje cell axons. $Z$. Zellforsch. 139: 1-10 (1972).

Cohen, C. M.: The molecular organization of the red-cell membrane skeleton. Sem. Hematol. 20: 141-158 (1983).

Cohen, R. S. and P. Siekevitz: Form of the postsynaptic density. A serial section study. J. Cell Biol. 78: 36-46 (1978).

Cohen, R. S., F. Blomberg, K. Berzins and P. Siekevitz : The structure of postsynaptic densities isolated from dog cerebral corex. I. Overall morphology and protein composition. J. Cell Biol. 74: 181-203 (1977).

Davis, J. Q. and BennetT, V.: Brain ankyrin. A membrane-associated protein with binding sites for spectrin, tubulin, and the cytoplasmic domain of the erythrocyte anion channel. J. Biol. Chem. 295: 1355013559 (1984).

ElgSAETER, A. and D. BRANTON: Intramembrane particle aggregation in erythrocyte ghosts. I. The effects of protein removal. J. Cell Biol. 63: 1018-1030 (1974).

Elgsaeter, A., D. Shotton and D. Branton: Intramembrane particle aggregation in erythrocyte ghosts. II. The influence of spectrin aggregation. Biochim. 
Biophys. Acta 426: 101-122 (1976).

Fawcett, D. W., W. A. Anderson and D. M. Phillips: Morphogenentic factors influencing the shape of the sperm head. Devel. Biol. 26: 220-251 (1971).

Fertuck, H. C. and M, M. Salpeter: Quantitation of junctional and extrajunctional acetylcholine receptors by electron microscopic autoradiography after ${ }^{125} \mathrm{I}-\alpha$ bungarotoxin binding at mouse neuromuscular junctions. J. Cell Biol. 69: 144-158 (1976).

Fine, R. E. and C. D. OCKLEFord: Supramolecular cytology of coated vesicles. Int. Rev. Cytol. 91: 1-43 (1984).

Fowler, V. M.: An actomyosin contractile mechanism for erythrocyte shape transformations. J. Cell. Biochem. 31: 1-9 (1986).

Fowler, V. M., J. Q. Davis and V. BennetT: Human erythrocyte myosin: Identification and purification. J. Cell Biol. 100: 42-55 (1985).

Fujimaki, N., Y. Kano and H. Ishikawa: The plasmalemmal undercoat at the end of skeletal muscle fibers. Cell Str. Funct. 10: 530 (1985).

mediate filaments with the sarcolemma in skeletal muscle fibers. In: Proc. 11th Int. Congr. Electron Microsc., Kyoto, 1986 (p. 2657-2658).

Geiger, B.: Membrane-cytoskeleton interaction. Biochim. Biophys. Acta 737: 305-341 (1983).

Glenney, J. R. and P. Glenney: Fodrin is the general spectrin-like protein found in most cells whereas spectrin and TW protein have a restricted distribution. Cell 34: 503-512 (1983).

Gully, R. L. and ReEse, T. S.: Cytoskeletal organization at the postsynaptic complex. J. Cell Biol. 91: 298 -302 (1981).

GuPtA, B. L. and M. J. BerRidge: A coat of repeating subunits of the cytoplasmic surface of the plasma membrane in the rectal papillae of the blowfly, Calliphora erythrocephala (Meig.), studied in situ by electron microscopy. J. Cell Biol. 29: 376-382 (1966).

Hainfeld, J. F. and T. L. Steck: The sub-membrane reticulum of the human erythrocyte. A scanning electron microscope study. J. Supramol. Str. 6: 301-311 (1977).

HAMA, K. and K. SAIto: Rectangular arrays of intramembranous paricles at the zonula adherens in the guinea pig organ of Corti. J. Electron Microsc. 25: 299302 (1976)

HeUser, J. F. and T. S. REESE: Evidence for recycling of synaptic vesicle membrane during transmitter release at the frog neuromuscular junction. J. Cell Biol. $57: 315$ -321 (1973).

Heuser, J. E., T. S. Reese and D. M. D. Landis: Functional changes in frog neuromuscular junctions studied with freeze fracture. J. Neurocytol. 3: 109-131 (1974).

Hirokawa, N. and J. E. Heuser: Internal and external differentiations of the postsynaptic membrane at the neuromuscular junction. J. Neurocytol. 11: 487-510 (1982).
Hynes, R. O.: Relationships between fibronectin and the cytoskeleton. In: (ed. by) G. Poste, and G. L. Nicolson : Cytoskeletal elements and plasma membrane organization. Elsevier, Amsterdam, 1981 (p. 99-137).

IsHIKAWA, H.: Identification and distribution of intracellular filaments. In: (ed. by) S. HATANO, H. IsHIKAWA, and H. SATO: Cell motility: molecules and organization. University of Tokyo Press, Tokyo, 1979 (p. 417444).

IsHIKAWA, H.: Fine structrure of skeletal muscle. In: (ed. by) R.M. Dowben and J.W. Shay: Cell and muscle motility. Vol. 4, Plenum Publishing Corp., New York, 1983 (p. 1-84).

Ishikawa, H., R. Bischoff and H. Holtzer: Formation of arrowhead complexes with heavy meromyosin in a variety of cell types. J. Cell Biol. 43: 312-328 (1969).

Ishikawa, H., S. Tsukita and S. Tsukita: Ultrastructural aspects of the plasmalemmal undercoat. In: (ed. by) G. Matsumoto and M. Kotani: Nerve membrane -Biochemistry and function of channnel proteins. University of Tokyo Press, Tokyo, 1981 (p. 167-183).

-: Association of the cytoskeleton with cell membranes-A concept of plasmalemmal undercoat. In: (ed. by) H. SAKAI, H. MoHrI and G. G. BorISY: Biological functions of microtubules and related structures. Academic Press, Tokyo-New York, 1982 (p. 377-389).

Ishimura, K., K. Egawa and H. Fujita: Freeze-fracture images of exocytosis and endocytosis in anterior pituitary cells of rabbits and mice. Cell Tiss. Res. 206: 233241 (1980).

Jimbu, Y., S. Sato: and M. Nakao: Reversible shape change of Triton-treated erythrocyte ghosts induced by $\mathrm{Ca}^{2+}$ and Mg-ATP. Nature 307: 376-378 (1984).

Kallio, D. M., P. R. Garant and C. Minkin: Evidence of coated membranes in ruffled border of the osteoclast. J. Ultrastr. Res. 37: 169-177 (1971).

Kano, Y., Saito, K. and Ishikawa, H.: Some observations of the fine structure of osteoclasts. Cell Str. Funct. 11: 474 (1986).

Kelly, A. M. and S. I. ZACKs: The fine structure of mouse end-plate morphogenesis. J. Cell Biol. 42: 154169 (1969).

KeLLY, D. E.: Fine structure of desmosomes, hemidesmosomes, and an epidermal globular layer in developing newt epidermis. J. Cell Biol. 28: 51-72 (1966).

KIRChHaUsen, T. and S. C. HARRISON : Protein organization in clathrin trimers. Cell 23: 755-761 (1981).

Kонno, K., R. Iто and Y. Momose: Undercoatings of axon initial segments (Japanese Abstract). Acta Anat. Nippon. 61: 560 (1986).

Langley, R. C., Jr. and C. M. Cohen: Association of spectrin with desmin intermediate filaments. J. Cell. Biochem. 30: 101-109 (1986).

LAZARIDEs, E.: Intermediate filaments as mechanical integrators of cellular space. Nature 283: 249-256 (1980).

LaZARIDES, E. and W. J. Nelson: Expression of spectrin 
in nonerythroid cells. Cell 31: 505-508 (1982).

LeBeux, Y. J. and J. Willemot: An ultrastructural study of the microfilaments in rat brain by means of E-PTA staining and heavy meromyosin labeling. II. The synapses. Cell Tiss. Res. 160: 37-68 (1975).

Lux, S. E.: Dissecting the red cell membrane skeleton. Nature 281: 426-429 (1979).

Mangeat, P. H. and K. BurRidge: Actin-membrane interaction in fibroblasts: What proteins are involved in this association. J. Cell. Biol. 99: 95s-103s (1984).

Marchesi, V. T.: The red blood membrane cytoskeleton: Recent progress. Blood 61: 1-11 (1983).

Marchesi, V. T., H. Furthmayr and M. Tomita: The red blood cell membrane. Annu. Rev. Biochem. 45: 667697 (1976).

Matus, A. I. and B. B. WALters: Ultrastructure of the synaptic junctional lattice isolated from mammalian brain. J. Neurocytol. 4: 369-375 (1975).

NAKaO, T.: Some observations on the fine structure of the myotendinous junction in myotomal muscles of the tadpole tail. Cell Tiss. Res. 166: 241-254 (1976).

Nelson, W. J and E. LAZARIDEs: Goblin (ankyrin) in striated muscle: Identification of the potential membrane receptor for erythroid spectrin in muscle cells. Proc. Nat. Acad. Sci. USA 81: 3292-3296 (1984).

Nermut, M. V.: Visualization of the "membrane skeleton" in human erythrocytes by freeze-etchig. Eur. J. Cell Biol. 25: 265-271 (1981).

Nicolson, G. L.: Transmembrane control of the receptors on normal and tumor cells. I. Cytoplasmic influence over cell surface components. Biochim. Biophys. Acta 457: 57-108 (1976).

Oschman, J. L. and M. J. Berridge: Structure and functional aspects of salivary secretion in Calliphora. Tiss. Cell 2: 281-310 (1970).

Palay, S. L.: The structural basis for neural action. In: (ed. by) M. A. B. Brazier: Brain function, Vol. II. University of California Press, Berkeley, 1964 (p. 69108).

Pappas, G. D. and S. G. Waxman: Synaptic fine structuremorphological correlates of chemical and electronic transmission. In: (ed. by) G. D. PAPpas and D. P. Purpura: Structure and function of synapses. Raven Press, New York, 1972 (p. 1-43).

Pearse, B. M. F.: Clathrin: a unique protein associated with intracellular transfer of membrane by coated vesicles. Proc. Nat. Acad. Sci. USA 73: 1255-1259 (1976).

Pearse, B. M. F. and M. S. Bretscher: Membrane recycling by coated vesicles. Annu. Rev. Biochem. 50: 85-101 (1981).

Peters, A.: The morphology of axons of the central nervous system. In: (ed. by) G.B. Bourne: The structure and function of nervous tissue, Vol. 1. Academic Press, New York and London, 1968 (p. 141-186).

Peters, A., S. L. Palay and H. de F. Webster: The fine structure of the nervous system. W.B. Sauders Co., Philadelphia, 1976.
Peters, A. and J. R. Kaiserman-Abmamof: The small pyramidal neuron of the rat cerebral cortex. Z. Zellforsch. 100: 487-506 (1969).

Pollard, T. D. and R. R. Weihing: Actin and myosin and cell movement. CRC Crit. Rev. Biochem. 2: 1-65 (1974).

Rayns, D. G., F. O. Simpson and J. M. LedinghaM: Ultrastructure of desmosomes in mammalian intercalated disc: Appearance after lanthanum treatment. J.Cell Biol. 42: 322-326 (1969).

Rosenbluth, J.: Intramembranous particle distribution at the node of Ranvier and adjacent adherence in myelinated axons of the frog brain. J. Neurocytol. 5: 731-745 (1976).

Sheetz, P. M. and SAwYer, D.: Triton shells of intact erythrocytes. J. Supramol. Str. 8: 399-412 (1978).

Shen, B. W., R. Josephs and T. L. STeck: Ultrastructure of unit fragments of the skeleton of the human erythrocyte membrane. J. Cell Biol. 99: 810-821 (1984).

SINGER, I. I.: The fibronexus: A transmembrane association of fibronectin-containing fibers and bundles of $5 \mathrm{~nm}$ microfilaments in hamster and human fibroblasts. Cell 16: 675-685 (1979).

- Association of fibronectin and vinculin with focal contacts and stress fibers in stationary hamster fibroblasts. J. Cell Biol. 92: 398-408 (1982).

Singer, S. L. and G. L. Nicolson: The fluid mosaic model of the structure of cell membranes. Science 175: 720-731 (1972).

Small, J. V.: Organization of actin in the leading edge of cultured cells. J. Cell Biol. 91: 695-605 (1981).

Small, J. V., G. Isenberg and J. E. Celis: Polarity of actin at the leading edge of cultured cells. Nature 272: 638-639 (1978)

Staenelin, A.: Structure and function of intracellular junctions. Int. Rev. Cytol. 39: 191-283 (1974).

STECK, T. L.: The organization of proteins in the human red blood cell membrane. J. Cell Biol. 62: 1-19 (1974).

: The band 3 protein of the human red blood cell membrane: A review. J. Supramol. Str. 8: 311-324 (1978).

Trotter, J. A., S. Eberhard and A. Samora: Structural domains of the muscle-tendon junction. 1. The internal lamina and the connecting domain. Anat. Rec. 207 : 573591 (1983).

Tsukita, S. and H. Ishikawa: The movement of membranous organelles in axons: Electron microscopic identification of anterogradely and retrogradely transported organelles. J. Cell Biol. 84: 513-530 (1980).

Tsukita, S. and S. Tsukita : Desmocalmin: a calmodulinbinding high molecular weight protein isolated from desmosomes. J. Cell Biol. 101: 2070-2080 (1985).

Tsukita, S., S. Tsukita and H. Ishikawa: Cytoskeletal network underlying the human erythrocyte membrane. Thin section electron microscopy. J. Cell Biol. 85: 568576 (1980). 
$10 \mathrm{~nm}$ filaments with the dense body in smooth muscle cells of the chicken gizzard. Cell Tiss. Res. 229: 233-242 (1983).

- - Bidirectional polymerization of G-actin on the human erythrocyte membrane. J. Cell Biol. 98 : 1102-1110 (1984).

Tsukita, S., S. Tsukita, H. Ishikawa, S. Sato and M. NAKAo: Electron microscopic study of reassociation of spectrin and actin with the human erythrocyte membrane. J. Cell Biol. 90: 70-77 (1981).

Ungewickell, E. and D. Branton: Assembly units of clathrin coats. Nature 298: 420-422 (1981).

Weldon, P. R. and M. W. Cohen: Development of synaptic ultrastructure at neuromuscular contacts in an amphibian cell culture system. J. Neurocytol. 8: 239-259 (1979).

Wong, A. J., D. P. Kiehart and T. D. Pollard: Myosin from human erythrocytes. J. Biol. Chem. 260: 46-49 (1985).

YAMADA, E.: Ultrastructure of biological membranes. Its morphology and variation as revealed by electron microscopy. J. Clin. Electron Microsc. 8: 5-6 (1975).
Yohro, T. and T. KamiYa : Luminal membrane specialization of the striated duct of the submandibular gland in the bat (Miniopterus schreibesi fulinous). Proc. Jap. Acad. 47: 427-431 (1971).

Prof. Harunori IsHIKAWA Department of Anatomy Gunma University School of Medicine 3-39-22 Showamachi, Maebashi 371 Japan

石川春 律

371 前橋市昭和町 3-39-22

群馬大学医学部

第二解剖学教室 